\title{
Experimental Deformation of Opalinus Clay at Elevated Temperature and Pressure Conditions: Mechanical Properties and the Influence of Rock Fabric
}

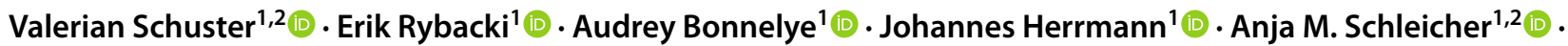 \\ Georg Dresen ${ }^{1,2}$ (D)
}

Received: 23 October 2020 / Accepted: 11 April 2021 / Published online: 11 May 2021

(C) The Author(s) 2021

\begin{abstract}
The mechanical behavior of the sandy facies of Opalinus Clay (OPA) was investigated in 42 triaxial tests performed on dry samples at unconsolidated, undrained conditions at confining pressures $\left(p_{\mathrm{c}}\right)$ of $50-100 \mathrm{MPa}$, temperatures $(T)$ between 25 and $200{ }^{\circ} \mathrm{C}$ and strain rates $(\dot{\varepsilon})$ of $1 \times 10^{-3}-5 \times 10^{-6} \mathrm{~s}^{-1}$. Using a Paterson-type deformation apparatus, samples oriented at $0^{\circ}$, $45^{\circ}$ and $90^{\circ}$ to bedding were deformed up to about $15 \%$ axial strain. Additionally, the influence of water content, drainage condition and pre-consolidation was investigated at fixed $p_{\mathrm{c}}-T$ conditions, using dry and re-saturated samples. Deformed samples display brittle to semi-brittle deformation behavior, characterized by cataclastic flow in quartz-rich sandy layers and granular flow in phyllosilicate-rich layers. Samples loaded parallel to bedding are less compliant compared to the other loading directions. With the exception of samples deformed $45^{\circ}$ and $90^{\circ}$ to bedding at $p_{\mathrm{c}}=100 \mathrm{MPa}$, strain is localized in discrete shear zones. Compressive strength $\left(\sigma_{\max }\right)$ increases with increasing $p_{c}$, resulting in an internal friction coefficient of $\approx 0.31$ for samples deformed at $45^{\circ}$ and $90^{\circ}$ to bedding, and $\approx 0.44$ for samples deformed parallel to bedding. In contrast, pre-consolidation, drainage condition, $T$ and $\dot{\varepsilon}$ do not significantly affect deformation behavior of dried samples. However, $\sigma_{\max }$ and Young's modulus $(E)$ decrease substantially with increasing water saturation. Compared to the clay-rich shaly facies of OPA, sandy facies specimens display higher strength $\sigma_{\max }$ and Young's modulus $E$ at similar deformation conditions. Strength and Young's modulus of samples deformed $90^{\circ}$ and $45^{\circ}$ to bedding are close to the iso-stress Reuss bound, suggesting a strong influence of weak clay-rich layers on the deformation behavior.
\end{abstract}

Keywords Clay rock $\cdot$ Sandy facies of Opalinus Clay $\cdot$ Triaxial deformation experiments $\cdot$ Microstructural deformation mechanisms $\cdot$ Pressure-, temperature- and strain rate-dependent mechanical behaviour $\cdot$ Anisotropy

\section{List of Symbols}

$\sigma_{1} \quad$ Maximum principal stress

$\theta \quad$ Angle between failure plane and samples axis

$\rho \quad$ Density

$\varphi \quad$ Porosity

$S_{w} \%$ Degree of water saturation

$T$ Temperature

$p_{c} \quad$ Confining pressure

$\dot{\varepsilon} \quad$ Strain rate

Valerian Schuster

valerian.schuster@gfz-potsdam.de

1 Helmholtz Centre Potsdam, GFZ German Research Centre for Geosciences, 14473 Potsdam, Germany

2 Institute for Earth and Environmental Science, University of Potsdam, 14476 Potsdam, Germany $t_{c} \quad$ Consolidation time

$L \quad$ Sample length

c Isotropic consolidation coefficient

$k \quad$ Hydraulic conductivity

$K \quad$ Bulk modulus

$\gamma_{w} \quad$ Unit weight of water

$E_{\text {oed }}$ Oedometer Young's modulus

$\nu \quad$ Poisson's ratio

E Secant Young's modulus

$B \quad$ Brittleness

$\sigma_{\max } \quad$ Peak (differential) strength

$\varepsilon_{\max } \quad$ Axial strain at peak strength

$\mu_{y} \quad$ Friction coefficient at yield stress

$n, \alpha \quad$ Constants

$\tau \quad$ Shear stress

$\tau_{0} \quad$ Cohesion

$\mu \quad$ Coefficient of internal friction at peak strength 


$\begin{array}{ll}\sigma_{n} & \text { Normal stress } \\ \sigma_{U C S} & \text { Uniaxial compressive strength } \\ \phi & \text { Friction angle } \\ t_{f} & \text { Required time to reach failure during drained } \\ & \text { shearing }\end{array}$

\section{Introduction}

Argillaceous rocks, claystones or shales mainly consist of clay minerals typically with $\geq 50$ volume percent (vol\%) of particles sized <62.5 $\mu \mathrm{m}$ (e.g., Folk 1980). They account for roughly two-thirds of the sedimentary rock record (Milliken 2014), and are encountered in different natural settings such as sedimentary basins (Hornby et al. 1994) and accretionary wedges (Yamaguchi et al. 2011; Chester et al. 2013; Morley et al. 2017). Clay-rich sedimentary rocks play also a fundamental role in many engineering applications, including the extraction of hydrocarbons as well as the exploitation of geothermal energy from unconventional deep shale reservoirs (e.g., Blackwell et al. 2013; McGlade et al. 2013). Due to a low hydraulic conductivity, high self-sealing potential as well as sorption capacity, clay-rich shales constitute potential host rocks for the storage of nuclear waste (Madsen 1998; Delage et al. 2010; Sellin and Leubin 2013), and represent a suitable cap-rock sealing for the geological storage of carbon dioxide (Busch et al. 2008; Boosari et al. 2015; Bourgh 2015).

Predicting the mechanical behavior and hydrological properties of clay rocks across several spatial and temporal scales requires knowledge of the processes leading to damage and failure at the respective thermodynamic boundary conditions. However, physical and mechanical properties of shales depend on many factors caused by their complex sedimentary and tectonic history. These factors include diagenetic processes influenced by chemical reactions, mechanical loading and temperature variations (Gutierrez et al. 1996; Bjørlykke and Høek 1997; Nygård et al. 2004; Wenk et al. 2008; Ilgen et al. 2017; Morley et al. 2017). Additionally, shales display an increased crystallographic and shape-preferred orientation of phyllosilicates, resulting in a distinct anisotropy of physical and mechanical properties related to the depositional and diagenetic conditions, mineral composition and thermal maturity (e.g., Chiarelli et al. 2000; Wenk et al. 2008; Sone and Zoback 2013; Siegesmund et al. 2014; Liu et al. 2018). Previous experimental studies show that the strength and elastic properties of clay-rich rocks depend on applied confining pressure (e.g., Ibanez and Kronenberg 1993; Niandou et al. 1997; Petley 1999; Naumann et al. 2007; Herrmann et al. 2018), temperature (e.g., Zhang et al. 2007; Masri et al. 2014; Rybacki et al. 2015; Liu et al. 2019), strain rate (e.g., Swan et al. 1989; Chong and Boresi 1990; Kwon and Kronenberg 1994; Al-Bazali et al. 2008;
Bonnelye et al. 2017a, b; Hou et al. 2019), and water content (e.g., Valès et al. 2004; Zhang et al. 2012; Wild et al. 2015; Zhang and Laurich 2019).

For the storage of nuclear waste, several European countries operate underground research laboratories (URL) to investigate the coupling of the different factors that control the response of the host rock during the construction and installation of a clay repository site (Delage et al. 2010; Tsang et al. 2012). The Opalinus Clay (OPA) formation is the envisaged host rock for geological disposal of radioactive waste in Switzerland (NAGRA 2002) and is also considered for a high-level nuclear waste repository in Germany (Jobmann et al. 2017). Under in situ conditions, OPA has been extensively studied at the Mont Terri Underground Research Laboratory (Switzerland), where three different main lithofacies types were identified within the formation: A shaly facies, a carbonate-rich sandy facies and a sandy facies (Thury and Bossart 1999; Pearson et al. 2003; Bossart and Milnes 2017; Lauper et al. 2018). For the safety assessment of OPA as a potential repository formation, prior laboratory deformation experiments have mainly focused on the characterization of the anisotropic and hydro-mechanically coupled behavior related to the excavation processes as well as on the determination of effective strength and stiffness parameters of the homogeneous, clay-rich shaly facies (e.g., Corkum and Martin 2007; Naumann et al. 2007; Popp and Salzer 2007; Amann et al. 2011, 2012; Wild et al. 2015; Zhang et al. 2017; Favero et al. 2018; Giger et al. 2018; Orellana et al. 2018, 2019; Wild and Amann 2018; Minardi et al. 2020). However, due to its higher elastic moduli, the sandy facies has recently gained importance in research (Kaufhold et al. 2013, 2016; Siegesmund et al. 2014; Minardi et al. 2016; Jaeggi et al. 2017; Zhang and Laurich 2019). The sandy facies of OPA displays a pronounced, fabric related heterogeneity that is characterized by an alternated bedding of quartz- and clay-rich layers (Peters et al. 2011; Kaufhold et al. 2013; Houben et al. 2014).

Detailed knowledge of rock mechanical behavior and elastic properties is necessary for modeling constructionrelated damage of a future repository site (e.g., Salager et al. 2013; Parisio et al. 2015). The development of constitutive models predicting long-term integrity and evolution of the host rock rests on micro-mechanical analysis to unravel the physical processes governing deformation (Bock et al. 2006). So far, little is known about deformation processes and micromechanics causing anisotropic rheological behavior of experimentally deformed OPA. Nüesch (1991) studied the mechanical behavior of shaly facies OPA at a range of confining pressures, temperatures and strain rates as well as the influence of water content on deformation perpendicular and parallel to bedding. Under the applied conditions, Nüesch concluded that deformation of OPA is largely governed by cataclastic flow. Previous studies were limited 
to macro- and mesoscale structures, due to difficult sample preparation of OPA (e.g., Klinkenberg et al. 2009; Amann et al. 2012; Kaufhold et al. 2013, 2016). More recent studies applied ion beam preparation tools like BIB/FIB (broad and focused ion beam) for the use of scanning electron microscopy (SEM) imaging, to resolve mineral and pore fabrics of shales and clays at the micro-scale (Keller et al. 2011, 2013a, b; Loucks et al. 2012; Houben et al. 2014; Laurich et al. 2014, 2017, 2018; Desbois et al. 2017, 2018; Philipp et al. 2017; Schuck et al. 2020). Desbois et al. (2018) described the microstructures of deformed shaly OPA samples from triaxial experiments conducted by Amann et al. (2012), revealing localized deformation with dilatant microcracking and cataclastic fabrics, dominated by granular flow and bending of phyllosilicates outside of the shear zone. So far, physical and mechanical properties of sandy facies OPA have not yet been characterized at similar resolution as shaly OPA.

In an effort to investigate the anisotropic mechanical behavior of sandy facies OPA, we performed a series of triaxial tests at varying confining pressures, temperatures and strain rates. Cylindrical samples were deformed either dry or re-saturated, and loaded in three different orientations of the sample with respect to bedding. Electron microscopy was performed on broad ion beam polished surfaces of deformed sample material to investigate the deformation microstructures formed in each sample orientation. A damage model is proposed that combines the observations from macro- to micro-scale with the failure behavior at test conditions. This study aims to contribute to the general understanding of anisotropic clay deformation related to compositional heterogeneity at different boundary conditions.

\subsection{Geological Setting and Material Description}

The investigated sample material belongs to the Opalinus Clay formation, an over-consolidated clay-rich shale that was collected from the Mont Terri URL. OPA has been deposited in a shallow marine environment during the late Toarcian to Aalenian about $180 \mathrm{Ma}$ ago (Reisdorf et al. 2014). Maximum burial depth of OPA at the Mont Terri URL was estimated to be about $1350 \mathrm{~m}$ in late-Tertiary with a maximum temperature of $85{ }^{\circ} \mathrm{C}$ reached during the early Cretaceous (Mazurek et al. 2006). The present overburden ranges between 230 and $330 \mathrm{~m}$ (Thury and Bossart 1999). The sedimentary, compaction and burial history of OPA led to a sub-parallel arrangement of clay platelets with respect to macroscopic bedding (Wenk et al. 2008). Due to this and the heterogeneity of macro- and microfabric in OPA, hydrological, microstructural, mechanical and transport-related properties exhibit transverse isotropy (e.g., NAGRA 2002; VanLoon et al. 2004; Gräsle and Plischke 2010, 2011; Keller et al. 2011, 2013b; Siegesmund et al. 2014; Keller and
Holzer 2018). Porosity estimates depend on resolution of the respective method, ranging between 4.9 and $19.1 \mathrm{vol} \%$ with best porosity estimates of $18 \mathrm{vol} \%$ and $11.1 \mathrm{vol} \%$ for the shaly and sandy facies, respectively. The average pore size is estimated between 2 and $20 \mathrm{~nm}$ equivalent pore diameter for both facies types (Thury and Bossart 1999; Minon et al. 2010; Peters et al. 2011; Keller et al. 2013a; Houben et al. 2014; Jaeggi et al. 2014; Philipp et al. 2017; Seiphoori et al. 2017). Permeability of the sandy and the shaly facies of OPA ranges between $2 \times 10^{-21}$ and $1 \times 10^{-19} \mathrm{~m}^{2}$ (NAGRA 2002; Bossart and Thury 2008; Philipp et al. 2017; Yu et al. 2017).

Samples used in this study were prepared from the sandy facies of OPA. At the URL, the sandy facies may be further separated into four sub types (cf., Müller and Jaeggi 2012), but can be generally described as a dark-gray silty to sandy claystone (Peters et al. 2011; Hostettler et al. 2017). The mineral composition of the sandy facies is dominated by clay minerals [6-70 weight percent (wt\%)], quartz (16-52wt\%), carbonates (7-66wt\%; mainly calcite, dolomite/ankerite and siderite) and feldspars (5-15wt\%). Clay minerals are mainly illite, kaolinite and chlorite (29-70wt\%), as well as illite-smectite mixed layers (5-20wt\%) (Thury and Bossart 1999; Pearson et al. 2003; Peters et al. 2011; Becker 2012; Zhang and Laurich 2019). Organic matter, rutile and apatite occur in minor amounts. The rock displays a wavy lamination of light gray layers and lenses of fine-grained quartz sand alternating with black clay-rich layers (Peters et al. 2011; Müller and Jaeggi 2012; Reisdorf et al. 2014). Some carbonate-rich lenses and bioclasts are embedded in a weak, macroscopically visible laminated matrix forming $\mathrm{mm}$ - to $\mathrm{dm}$-scale heterogeneous layers (Kaufhold et al. 2013, 2016; Houben et al. 2014; Jaeggi et al. 2014). Compared to the shaly facies, the sandy facies of OPA is typically rather heterogeneous and displays larger mineral clasts (silt to fine-sand fraction) as well as a higher content of quartz and carbonates with generally lower amounts of clay minerals (Thury and Bossart 1999; Pearson et al. 2003; Klinkenberg et al. 2009; Minon et al. 2010; Gräsle and Plischke 2011; Kaufhold et al. 2013; Minardi et al. 2016; Bossart and Milnes 2017).

\section{Methods}

\subsection{Sample Preparation and Characterization}

The sample material was provided by Swisstopo (Federal Office for Topography, Wabern, Switzerland) and originates from borehole BFI-1 located in Gallery 04 (Mont Terri URL). Drilling of $101 \mathrm{~mm}$ diameter cores was carried out parallel to the local bedding orientation under dry conditions using compressed air as a cooling fluid. To prevent desaturation after extraction, cores were subsequently stored 
in plastic liners wrapped in aluminum foil, and vacuum sealed. Samples obtained in this study were taken from a $25 \mathrm{~cm}$ long core section drilled about $8 \mathrm{~m}$ into the gallery wall. We prepared cylindrical specimens of $10 \mathrm{~mm}$ diameter and $20 \mathrm{~mm}$ length with parallel end faces for triaxial tests. Several samples were first dried at $110^{\circ} \mathrm{C}$ until a constant weight was reached, resulting in an average water content of $4.2 \pm 0.6 \mathrm{wt} \%$ for fresh core material. Samples were drilled at an angle of $0^{\circ}, 45^{\circ}$ and $90^{\circ}$ to cylinder axis and bedding direction, further referred to as $\mathrm{p}-$, $\mathrm{z}$ - and s-samples, respectively (Fig. 9a, e, i). To prevent cracking, the majority of tested samples were carefully dried at $50{ }^{\circ} \mathrm{C}$ at a relative humidity (RH) of about $22 \pm 5 \%$ until constant weight was reached. Further drying of sub-samples at $110^{\circ} \mathrm{C}$ for $>48 \mathrm{~h}$ revealed a residual water content of about $0.4 \mathrm{wt} \%$ on average for 'dry' samples.

To investigate the influence of water content on the mechanical behavior, one set of $\mathrm{p}-$, $\mathrm{z}$ - and s-samples was stored in a desiccator at room temperature exposed to a relative humidity of $95 \pm 5 \%$ for up to 5 weeks. To achieve the desired humidity, we employed a vapor equilibrium technique using a supersaturated $\mathrm{K}_{2} \mathrm{SO}_{4}$-solution (e.g., Laloui et al. 2013). Bulk density of cylindrical samples was determined from the ratio of weight and volume. For dry samples, values range between 2.34 and $2.44 \mathrm{~g} / \mathrm{cm}^{3}$ (average: $2.37 \pm 0.02 \mathrm{~g} / \mathrm{cm}^{3}$ ) and for saturated samples, densities were 2.44-2.47 g/ $\mathrm{cm}^{3}$ (average: $2.45 \pm 0.04 \mathrm{~g} / \mathrm{cm}^{3}$ ). We used a He-pycnometer (Micromeritics, AccuPyc 1340) to calculate the connected porosity of dried specimens via bulk and skeletal volume, resulting in porosities between 7.7 and $13.5 \mathrm{vol} \%$ (average: $12.3 \pm 1.2 \mathrm{vol} \%$ ). Obtained values for porosity, grain and bulk density are consistent with previous data for the sandy facies of OPA (Peters et al. 2011; Yu et al. 2017; Zhang and Laurich 2019). The degree of saturation was estimated from the ratio of volumetric water content and total porosity (cf., Amann et al. 2011), yielding values of $94.6-97.9 \%$ (average: $96.1 \pm 1.3 \%$ ) after the saturation procedure.

Four sub-samples from the drilled core section containing all samples were used to determine the bulk mineral composition by X-ray diffraction analysis (XRD) (Table 1). Analysis was performed using a PANalytical Empyrean $\mathrm{X}$-ray diffractometer, operating at $40 \mathrm{kV}$ and $40 \mathrm{~mA}$ with
$\mathrm{Cu}-\mathrm{K} \alpha$ radiation and a step size of $0.013^{\circ} 2 \theta$ from 4.6 to $85^{\circ}$. The mineralogy was first determined with the software EVA (version 11.0.0.3) by Bruker. Rietveld refinement for quantitative analysis was performed using the program BGMN and the graphical user interface Profex (version 3.10.2, Döbelin and Kleberg 2015). The error is expected to be in the range of $3 \mathrm{wt} \%$.

Bulk mineralogy (Table 1) reveals quartz (samples 101-205) or clay-rich domains (sample 2011), consistent with the mineral composition described in literature and reflecting the spatial heterogeneity of sandy facies. We further quantified the mineralogy of individual black clay-rich and light gray sand-rich layers using sub-samples retrieved from the raw material, directly extracted from the core without further treatment as well as from deformed specimens tested at different temperatures (cf., chapter 3.1.3). The results reveal some compositional variability between both layer types, whereas sand layers display a higher quartz $(47 \pm 3 \mathrm{wt} \%)$ and carbonate $(16 \pm 6 \mathrm{wt} \%)$ content in average and clay-rich layers, a comparable increased mean clay content of $45 \pm 10 \mathrm{wt} \%$ (Table 2).

Deformed samples were embedded in epoxy resin and cut perpendicular to the macroscopically visible shear plane and parallel to the $\sigma_{I}$-direction using a low-speed microdiamond saw (Fig. 1). Subsequently, surfaces of half cut samples were hand-polished. Reflected light optical scans of the deformed samples were made using a Leica DM RX microscope. For each sample we measured the angle between failure plane and loading direction $(\theta)$. Based on macroscopic inspection, rectangular shaped sub-samples $\left(11 \times 8 \times 3 \mathrm{~mm}^{3}\right)$ were cut for further broad ion beam polishing. Resulting sections were pre-polished under dry conditions with $\mathrm{SiC}$ grinding paper down to $\mathrm{P} 4000$ grade. BIB-polished surfaces were prepared using a JEOL IB-19520CCP polisher at low pressure $\left(4 \times 10^{-4} \mathrm{~Pa}\right)$ conditions. Polishing time was $2 \mathrm{~h}$ at $8 \mathrm{kV}$ $200 \mu \mathrm{A}$ and $6 \mathrm{~h}$ at $6 \mathrm{kV}, 150 \mu \mathrm{A}$, which removed a layer of approximately $100 \mu \mathrm{m}$ thickness. The sizes of resulting BIB cross sections were about $2.5 \mathrm{~mm}^{2}$, prepared parallel to loading direction (Fig. 1). Furthermore, several BIB cross sections of undeformed material were prepared using the same procedure. Microstructural observations on carbon-coated BIB cross sections were performed with a FEI Quanta 3D Dual Beam scanning electron microscope (SEM) at $20 \mathrm{kV}$
Table 1 Petrophysical properties and bulk mineralogy of the investigated sample material obtained from subsamples of the drilled core section

\begin{tabular}{llllllll}
\hline Sample ID & $\rho\left(\mathrm{g} / \mathrm{cm}^{3}\right)$ & $\varphi(\mathrm{vol} \%)$ & Clay (wt\%) & Quartz (wt\%) & $\begin{array}{l}\text { Carbon- } \\
\text { ates }(\mathrm{wt} \%)\end{array}$ & $\begin{array}{l}\text { Feldspar } \\
(\mathrm{wt} \%)\end{array}$ & Pyrite (wt\%) \\
\hline 101 & 2.39 & 12.9 & 17 & 54 & 20 & 10 & $<1$ \\
204 & 2.39 & 11.8 & 16 & 55 & 20 & 9 & $<1$ \\
205 & 2.37 & 12.7 & 28 & 50 & 13 & 9 & $<1$ \\
2011 & 2.37 & 12.4 & 53 & 37 & 5 & 6 & $<1$ \\
\hline
\end{tabular}

$\rho$ Density, $\varphi$ porosity 
acceleration voltage and $5 \mathrm{~mm}$ working distance. Semiquantitative geochemical analysis was conducted with an attached EDAX energy-dispersive X-ray analyzer (EDX).

Depending on layer composition, the size of clastic minerals increases from $<30 \mu \mathrm{m}$ in clay dominated layers up to $80 \mu \mathrm{m}$ in sand-rich layers and lenses (Fig. 2a, b). Sandy domains regularly display high amounts of blocky calcite or kaolinite cement, filling the space between detrital quartz (Fig. 2b). However, diagenetic cementation of the clay-rich matrix is weak (cf., Corkum et al. 2007; Seiphoori et al. 2017).

At SEM resolution, visible pores are mainly located in the clay matrix (Fig. 2a-c). Size and orientation of single pores depends on matrix compaction and orientation of single clay
Table 2 Mineral composition of sand- and clay-rich layers, extracted from samples tested at different temperature conditions (cf., chapter 3.1.3) as well as from raw material

\begin{tabular}{llrllclc}
\hline Sample ID & Layer type & $T\left({ }^{\circ} \mathrm{C}\right)$ & Clay (wt\%) & Quartz (wt\%) & $\begin{array}{l}\text { Carbon- } \\
\text { ates }(w t \%)\end{array}$ & $\begin{array}{l}\text { Feldspar } \\
(\mathrm{wt} \%)\end{array}$ & Pyrite (wt\%) \\
\hline Raw & Sand layer & 25 & 26 & 48 & 19 & 8 & $<1$ \\
OT1B & Sand layer & 50 & 37 & 50 & 8 & 6 & $<1$ \\
OT23 & Sand layer & 100 & 28 & 44 & 22 & 7 & $<1$ \\
OT13B & Sand layer & 200 & 29 & 47 & 16 & 8 & $<1$ \\
Raw & Clay layer & 25 & 42 & 40 & 10 & 8 & $<1$ \\
OT1B & Clay layer & 50 & 41 & 38 & 9 & 13 & $<1$ \\
OT23 & Clay layer & 100 & 59 & 27 & 9 & 5 & $<1$ \\
OT13B & Clay layer & 200 & 36 & 41 & 16 & 7 & $<1$ \\
\hline
\end{tabular}

$T$ temperature
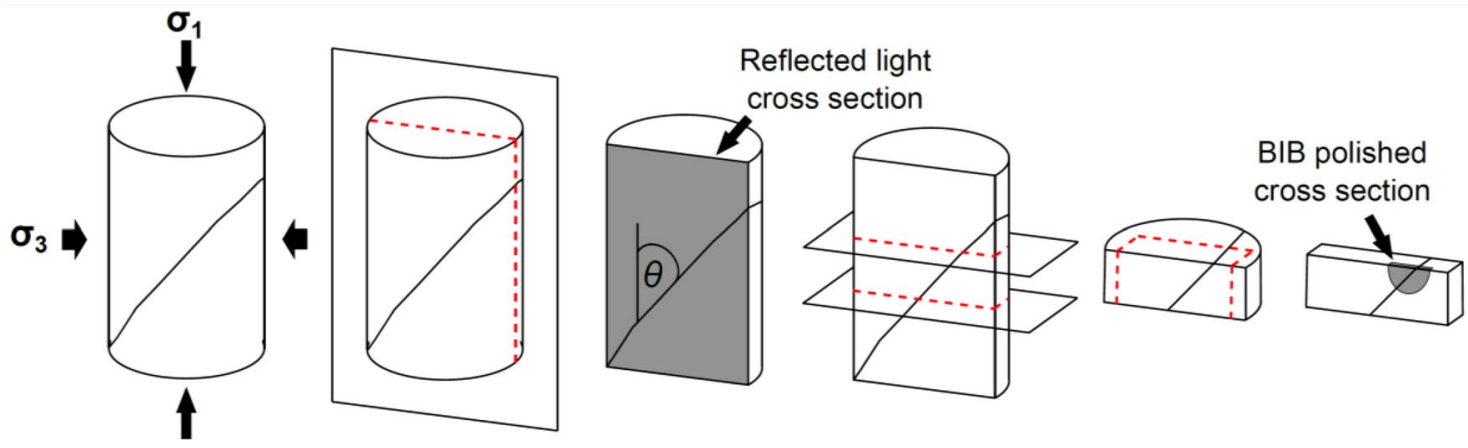

Fig. 1 Overview of the preparation procedure (from left to right) for reflected light and BIB-SEM microstructural investigation of deformed samples. Dotted lines indicate cutting planes. $\theta$ is the angle between failure plane and loading direction. Figure is not to scale
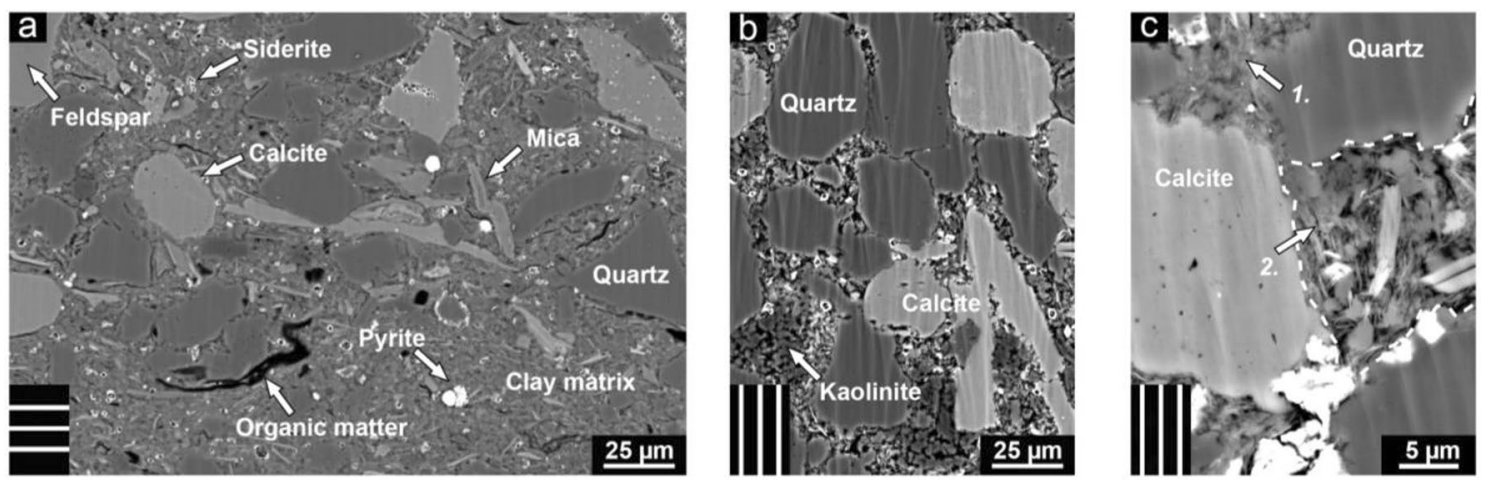

Fig. 2 Backscattered electron images of undeformed Opalinus Clay of the sandy facies $(\mathbf{a}-\mathbf{c})$ with bedding orientation indicated in the black boxes at the bottom left of each picture. a Clay layer showing characteristic mineral phases surrounded by clay matrix, barely touching each other. b Sand layer showing quartz grains cemented by kaolinite and blocky calcite. c Differences in the orientation and compaction of clay particles in clay matrix (1) and in areas of grainsupported framework (2) 
particles. In clay-rich layers, individual clay platelets are densely packed within the matrix and contain interparticle pores, both of which are aligned sub-parallel to the macroscopically visible bedding orientation. In contrast, the matrix as well as the kaolinite cement barely show compaction where clasts build a grain-supported framework (Fig. 2b, c). Here, clay particles show a random orientation with larger interparticle pores compared to the matrix-supported domains (Fig. 2c).

\subsection{Experimental Methods}

Triaxial deformation experiments were performed over a wide range of temperatures $\left(T=25-200{ }^{\circ} \mathrm{C}\right)$ and confining pressures $\left(p_{c}=50-100 \mathrm{MPa}\right)$ at constant strain rates $(\dot{\varepsilon})$ ranging from $1 \times 10^{-3}$ to $5 \times 10^{-6} \mathrm{~s}^{-1}$, using a Paterson-type deformation apparatus (Paterson 1970). Specimens were contained in copper jackets with a thickness of $0.35 \mathrm{~mm}$, which prevented intrusion of the confining pressure medium (argon gas). Specimens were heated at a rate of $20{ }^{\circ} \mathrm{C} / \mathrm{min}$ using a three-zone oven installed inside the pressure vessel (Paterson 1970) after the confining pressure was applied. Axial stress was calculated from the internally recorded axial force, which was corrected for copper jacket strength, assuming constant volume deformation. Axial strain was determined from external linear-variable displacement transducer (LVDT) readings, corrected for system compliance. Estimated uncertainties of resulting stress and strain values are $<4 \%$ and $<6 \%$, respectively (cf., Rybacki et al. 2015; Herrmann et al. 2018).

Samples were tested at undrained conditions and were not pre-consolidated prior to testing. For this, impermeable aluminum oxide spacers were placed at both ends of the specimens. Furthermore, to estimate the influence of drainage conditions and pre-consolidation on strength of dried samples (that contain a small amount of $\sim 0.4 \mathrm{wt} \%$ residual water), we used both permeable and impermeable spacers in the assembly and deformed three dried p-samples at $p_{c}=50 \mathrm{MPa}, T=100{ }^{\circ} \mathrm{C}$ and $\dot{\varepsilon}=5 \times 10^{-4} \mathrm{~s}^{-1}$. For drained conditions, we used permeable aluminum oxide spacers with a porosity of approximately $25 \mathrm{vol} \%$. Samples were consolidated at $p_{c}=50 \mathrm{MPa}$ and $T=100{ }^{\circ} \mathrm{C}$ for $\sim 18 \mathrm{~h}$. To check whether the applied consolidation time was sufficient, we estimated the theoretical minimum consolidation time $\left(t_{c}\right)$ using the expression $t_{c}=0.196 \times L^{2} / c$ (Bishop and Henkel 1962). $L$ is sample length and $c$ is the coefficient of isotropic consolidation. For s-samples $t_{c}$ is about $11 \mathrm{~h}$ using an isotropic consolidation coefficient of $c \approx 0.002 \mathrm{~mm}^{2} \mathrm{~s}^{-1}$. The coefficient $c$ was calculated following the procedure suggested by Head and Epps (2014) using the relation $c=(k \times K) / \gamma_{w}$, where $K$ is the bulk modulus, $k$ is the hydraulic conductivity and $\gamma_{\mathrm{w}}$ is the unit weight of water. The bulk modulus was estimated from the oedometer Young's modulus $\left(E_{\text {oed }}\right)$ measured by Ferrari et al. (2016) in highpressure oedometric compression tests on Opalinus Clay. Both quantities are related by $K / E_{\text {oed }}=(1+\nu) /(3 \times(1-\nu))$ assuming an isotropic material with linear elastic behavior. The drained Poisson's ratio is assumed to be $\nu=0.25$ and the hydraulic conductivity $k=1 \times 10^{-14} \mathrm{~ms}^{-1}$ (cf., Amann et al. 2015).

The Young's modulus $E$ was determined using the secant method. To this end, the slope of corrected axial strain-differential stress curves was determined between origin and strain at $50 \%$ peak stress. Due to the low stiffness of the Paterson apparatus, the accuracy of $E$ estimated from calibration runs is $<20 \%$ (Herrmann et al. 2018). The yield point was determined from stress-strain plots, where the differential stress graph deviates from linearity. In addition, we estimated brittleness $B$, which is commonly used in petroleum engineering to classify the mechanical behavior of reservoir rocks into brittle (1) and ductile (0) deformation (Holt et al. 2011). $B$ was calculated from the ratio of elastic strain to strain at peak strength (Rybacki et al. 2016) and was used to characterize the pre-failure behavior of the tested samples. It should be mentioned that the brittleness index is an empirical parameter based on a variety of existing definitions related to rock composition, deformation behavior or elastic properties (Rybacki et al. 2016; Zhang et al. 2016). The estimated error of determined $B$ is about $30 \%$ (cf., Rybacki et al. 2016).

\section{Results}

We performed 42 triaxial deformation experiments at varying confining pressure, temperature and strain rate. Tests were done on cylindrical samples of the sandy facies of dry OPA with three different loading orientations $\left(0^{\circ}, 45^{\circ}\right.$ and $90^{\circ}$ ) with respect to bedding. In addition, we investigated the influence of water content, pre-consolidation and drainage condition on the deformation behavior at selected boundary conditions on the deformation behavior at selected boundary conditions.

\subsection{Mechanical Behavior Under Triaxial Conditions}

\subsubsection{Effect of Pre-consolidation and Drainage Condition}

To examine the influence of drainage conditions on the deformation behavior, we deformed dried and saturated p-samples $\left(0^{\circ}\right.$ towards bedding $)$ at $p_{\mathrm{c}}=50 \mathrm{MPa}, T=100{ }^{\circ} \mathrm{C}$ and $\dot{\varepsilon}=5 \times 10^{-4} \mathrm{~s}^{-1}$ at both drained and undrained conditions. Independent of the applied drainage condition, dry samples exhibit almost identical deformation behavior (Fig. 3a, Table 3). In contrast, for saturated samples, strength $\sigma_{\max }$ and axial strain at peak strength $\varepsilon_{\max }$ are strongly 
reduced at drained compared undrained conditions. Also, the Young's modulus of saturated samples is slightly lower at drained compared to undrained conditions, whereas brittleness was not affected for dry and saturated samples at both applied conditions (Table 3).

To test the effect of pre-consolidation on deformation, p-samples were tested at similar deformation conditions using both permeable and impermeable spacers. No significant change of the mechanical behavior was observed if samples were pre-consolidated at undrained conditions (cp., Fig. 3a, b). On the other hand, the pre-consolidated sample tested at drained conditions displayed an increase of the peak strength by about $14 \%$ and about $20 \%$ of the Young's modulus (Fig. 3b). Again, brittleness was not affected.

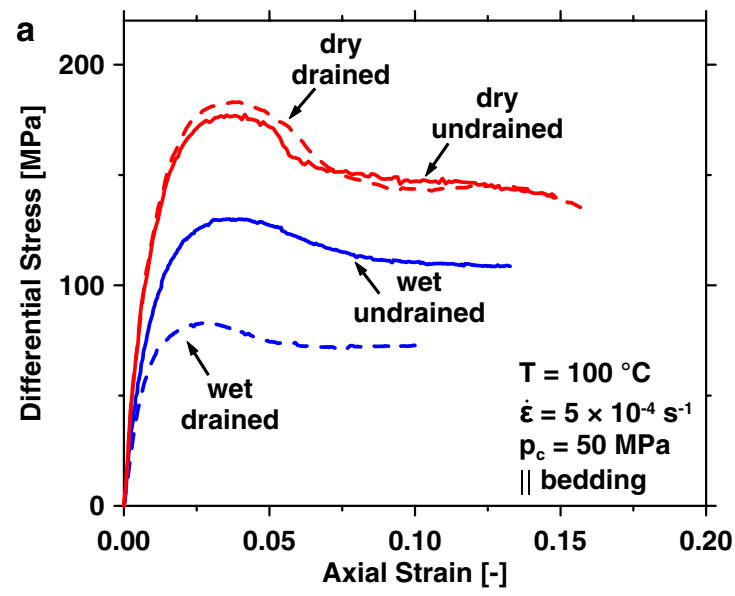

Fig. 3 Influence of drainage condition on dry and saturated samples (a) as well as the effect of pre-consolidation on dried samples at different drainage conditions (b). Undrained and drained conditions
Our results indicate a minor influence of drainage condition and pre-consolidation on the deformation behavior of dried samples. Therefore, most tests were conducted on dry samples at different pressure, temperature and strain rates at undrained conditions without pre-consolidation.

\subsubsection{Effect of confining Pressure and Bedding Orientation}

To investigate the effect of pressure on the mechanical properties of OPA, we deformed dried samples in all three orientations at constant strain rate of $\dot{\varepsilon}=5 \times 10^{-4} \mathrm{~s}^{-1}$ and temperature of $T=100{ }^{\circ} \mathrm{C}$, applying confining pressures of $p_{\mathrm{c}}=50,75$ and $100 \mathrm{MPa}$. Stress-strain curves of tested samples show that the mechanical behavior of OPA is strongly

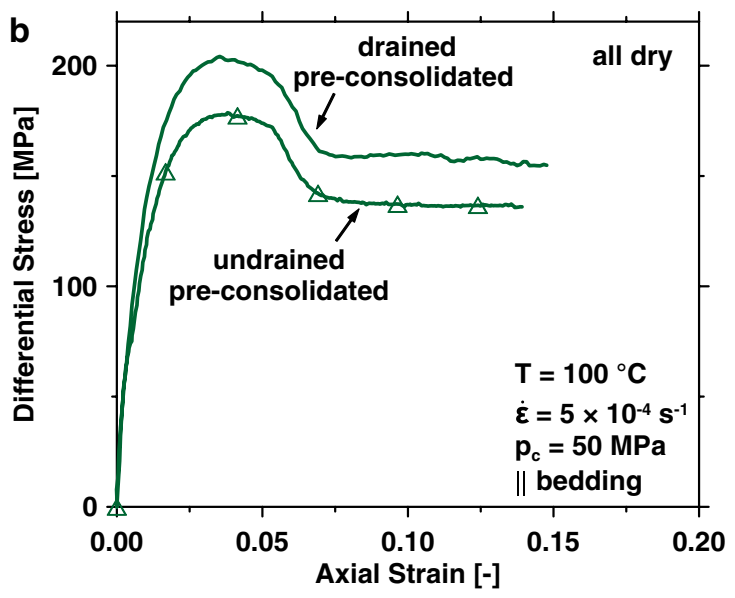

refer to the use of low and high porous spacers. Deformation conditions and sample orientation are indicated

Table 3 Petrophysical parameters and mechanical data of samples deformed at $p_{c}=50 \mathrm{MPa}, T=100{ }^{\circ} \mathrm{C}, \dot{\varepsilon}=5 \times 10^{-4} \mathrm{~s}^{-1}$ with different saturation degree $S_{w}$ as well as drainage condition and pre-consolidation

\begin{tabular}{|c|c|c|c|c|c|c|c|c|c|}
\hline Sample ID & $\begin{array}{l}\text { Sample } \\
\text { orientation }\end{array}$ & Sample condition & $\rho\left(\mathrm{g} / \mathrm{cm}^{3}\right)$ & $\varphi(\operatorname{vol} \%)$ & $\sigma_{\max }(\mathrm{MPa})$ & $\varepsilon_{\max }(\%)$ & $E(\mathrm{GPa})$ & $B(-)$ & $\theta\left(^{\circ}\right)$ \\
\hline OT02 & $\mathrm{p}$ & dry & 2.36 & 12.1 & 177 & 3.45 & 15.2 & 0.34 & $33^{\prime}$ \\
\hline OT11 & $\mathrm{p}$ & $\begin{array}{l}\text { dry } \\
\text { drained }\end{array}$ & 2.35 & 13.2 & 183 & 3.91 & 15.1 & 0.31 & $29 ’$ \\
\hline OT04 & $\mathrm{p}$ & $S_{w}=97.9 \%$ & 2.46 & $13.8^{*}$ & 130 & 3.64 & 10.1 & 0.35 & $30^{\prime}$ \\
\hline OT21 & $\mathrm{p}$ & $\begin{array}{l}S_{w}=95.6 \% \\
\text { drained }\end{array}$ & 2.44 & $14.3^{*}$ & 83 & 2.87 & 9.2 & 0.32 & 33 \\
\hline OT06 & $\mathrm{p}$ & $\begin{array}{l}\text { dry } \\
t_{c}=17: 40 \mathrm{~h}\end{array}$ & 2.36 & 12.4 & 179 & 3.78 & 13.8 & 0.34 & 28 \\
\hline OT12 & $\mathrm{p}$ & $\begin{array}{l}\text { dry, drained } \\
t_{c}=18: 50 \mathrm{~h}\end{array}$ & 2.35 & 13.2 & 204 & 3.47 & 16.5 & 0.36 & $26{ }^{\prime}$ \\
\hline
\end{tabular}

$\rho$ density, $\varphi$ porosity, $\sigma_{\max }$ peak strength, $\varepsilon_{\max }$ strain at peak strength, $E$ Young's modulus, $B$ brittleness, $\theta$ angle between failure plane and loading direction,' two failure planes, $S_{w} \%$ degree of saturation, $t_{c}$ consolidation time. $\mathrm{p}\left(0^{\circ}\right), \mathrm{z}\left(45^{\circ}\right)$ and s $\left(90^{\circ}\right)$ represent the sample orientation between the loading direction relative to the bedding plane. ${ }^{*}$ determined from sub-samples after drying at $110{ }^{\circ} \mathrm{C}$. Drained refers to the use of high porous spacers 
affected by confining pressure as well as by sample orientation with respect to bedding (Figs. 4a-c, 5).

P-samples (Fig. 4a) show macroscopically brittle to semi-brittle deformation behavior with low yield strain and extended non-linear strain hardening before peak stress
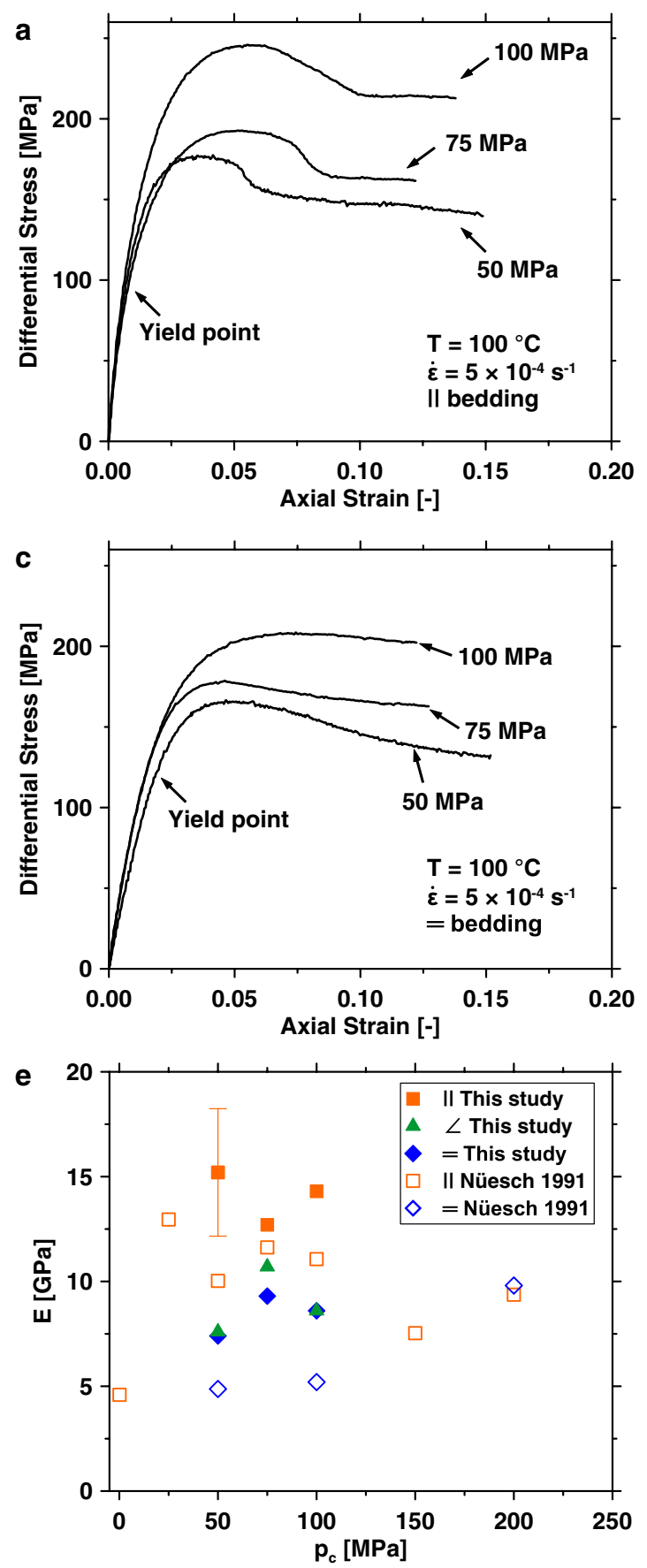

Fig. 4 Stress-strain curves showing the influence of confining pressure $p_{c}$ on deformation behavior of the sandy facies samples (this study, solid symbols) deformed parallel (a), $45^{\circ}$ (b) and perpendicular (c) to bedding direction as well as the relation between confining pressure $p_{c}$ and peak strength $\sigma_{\max }$ (d) Young's modulus $E(\mathbf{e})$
(Evans and Kohlstedt 1995). Beyond failure, p-samples exhibit relatively distinct strain weakening down to a steady residual differential stress. In comparison, samples oriented at $45^{\circ}$ (Fig. 4b) and perpendicular (Fig. 4c) to bedding showed more ductile behavior yielding at higher strain.
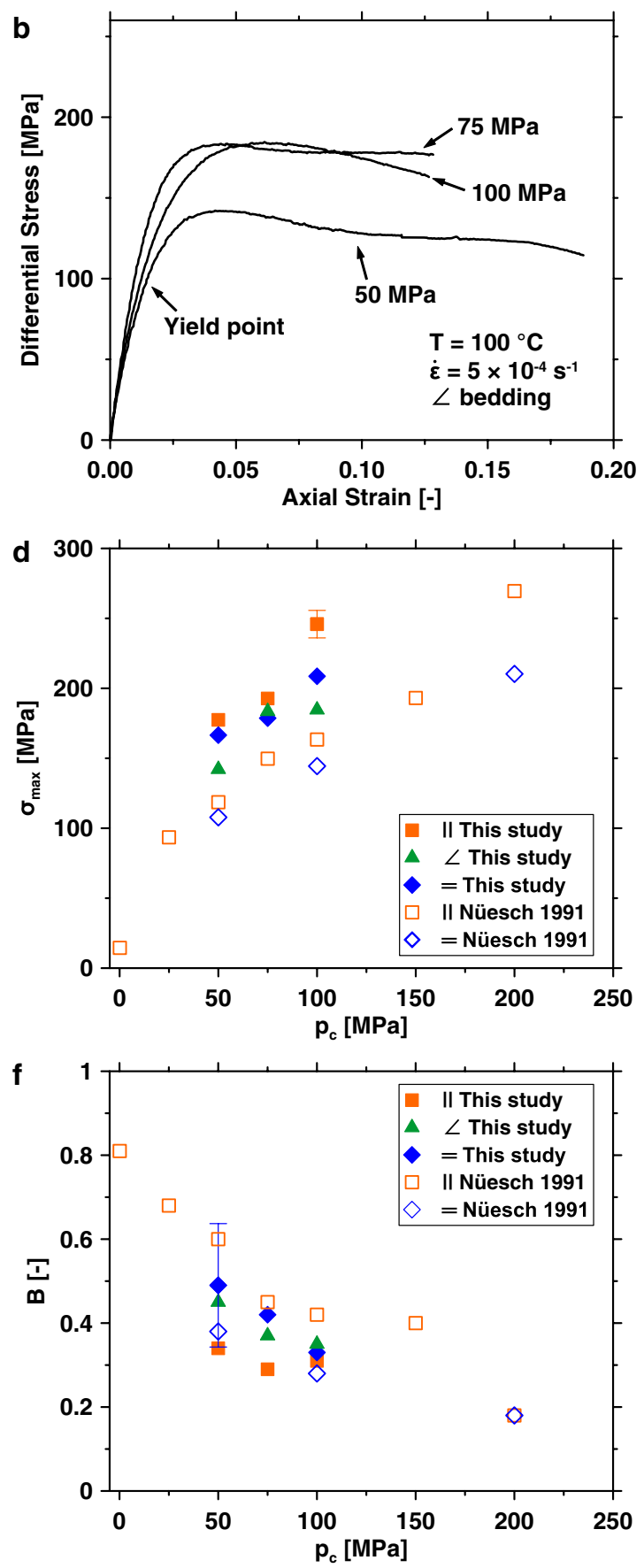

and brittleness $B$ (f) in comparison to the shaly facies deformed at $T=20{ }^{\circ} \mathrm{C}$ and $\dot{\varepsilon}=10^{-4} \mathrm{~s}^{-1}$ (Nüesch 1991). Deformation conditions and sample orientation are indicated. Yield point in $\mathbf{a}-\mathbf{c}$ is indicated for each sample orientation deformed at $p_{c}=50 \mathrm{MPa}$ 

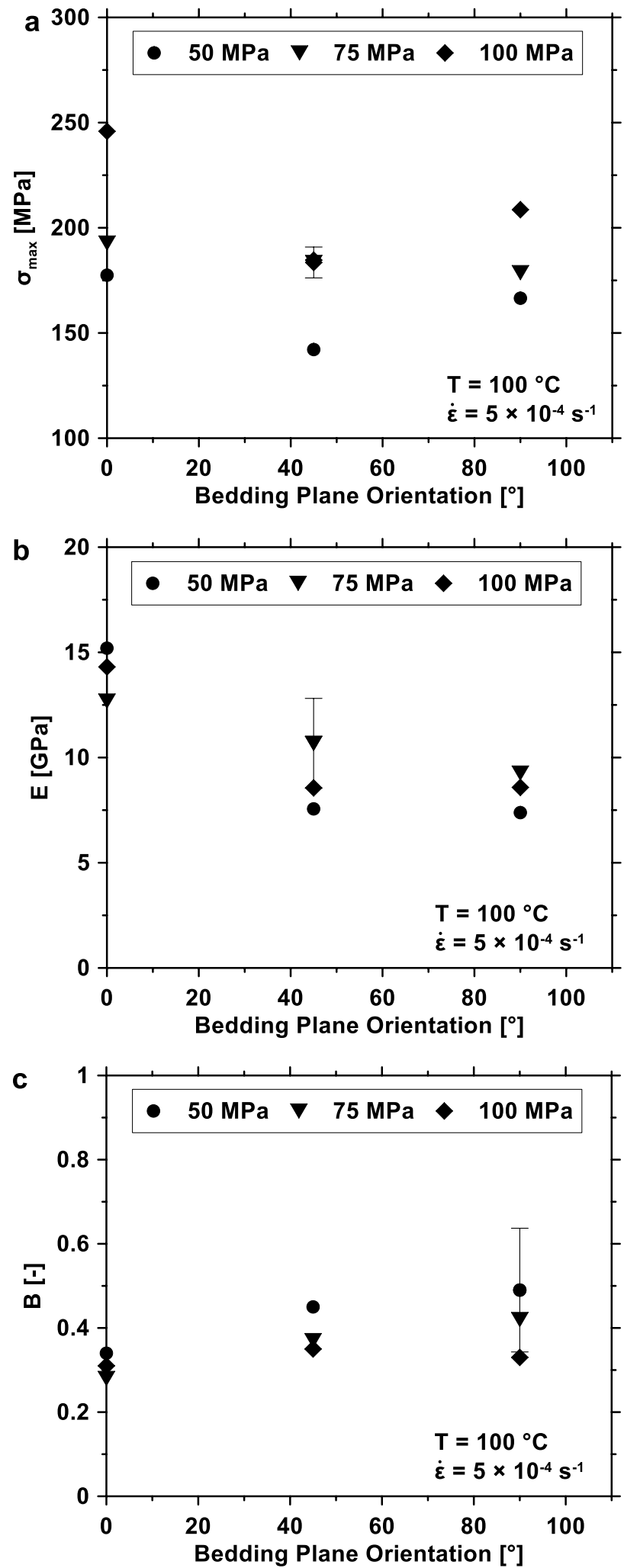

Fig. 5 Variation of peak strength $\sigma_{\max }(\mathbf{a})$, Young's modulus $E(\mathbf{b})$ and brittleness $B$ (c) as a function of the orientation between bedding plane and loading direction. Deformation conditions are indicated
These samples show minor post-peak weakening, in particular at elevated confining pressures $\left(p_{c} \geq 75 \mathrm{MPa}\right)$.

In general and independent of the bedding orientation, the samples showed increasing peak strength $\sigma_{\max }$ (Fig. 4d) and axial strain at peak strength $\varepsilon_{\max }$ (Table 4) with increasing confining pressure. Strain at peak strength of z- and s-samples was most affected by confining pressure.

No systematic correlation was found between calculated static Young's modulus and applied confining pressure (Fig. 4e) for all sample orientations. In contrast, $B$ of $\mathrm{z}$ - and s-samples decreased with increasing $p_{\mathrm{c}}$ (Fig. 4f). The brittleness index of p-samples remained almost constant with increasing confining pressure. It ranged between 0.29 and 0.34 , indicating relatively ductile pre-failure deformation behavior of p-samples.

In Fig. 5, we compare the values of peak strength, Young's modulus and brittleness obtained at different confining pressures as a function of bedding orientation with respect to the loading direction. For sandy facies OPA, highest peak strength is obtained in samples oriented parallel to bedding. Minimum strength was found for samples oriented $45^{\circ}$, as commonly observed for transversely isotopic materials (e.g., Ibanez and Kronenberg 1993; Niandou et al. 1997; Naumann et al. 2007; Islam and Skalle 2013; Lisjak et al. 2014). However, strength anisotropy is small and ranges between $\sigma_{\max p} / \sigma_{\max z, s}=1.0-1.3$. Young's modulus decreased continuously with increasing inclination of the bedding plane to loading orientation (Fig. 5b). The elastic anisotropy was found to be higher than the strength anisotropy $\left(E_{\mathrm{p}} / E_{z, s}=1.2-2.1\right)$. P-samples display highest Young's moduli (12.7-15.2 GPa), while Young's moduli of z- and s-samples are comparable and in the range of 7.4-10.7 GPa. Brittleness, as defined in this study, shows minor anisotropy at low confinement of $50 \mathrm{MPa}\left(B_{\mathrm{p}} / B_{s}=0.7\right)$ and almost no influence of orientation at $p_{c}=100 \mathrm{MPa}$ (Fig. 5c).

\subsubsection{Effect of Temperature}

To determine the effect of temperature $(T=25,50,100$, 150 and $200{ }^{\circ} \mathrm{C}$ ) on the mechanical properties of dried OPA samples, deformation experiments were performed at fixed confining pressure and constant strain rate conditions of $p_{\mathrm{c}}=50 \mathrm{MPa}$ and $\dot{\varepsilon}=5 \times 10^{-4} \mathrm{~s}^{-1}$, respectively. The results reveal that strength, elasticity and brittleness of the sandy facies were not significantly affected by varying temperatures up to $200{ }^{\circ} \mathrm{C}$ (Table 5, Fig. 6).

Stress-strain curves of all sample orientations were almost independent of temperatures and showed only minor differences (Fig. 6a-c), with the exception of one low porous p-sample deformed at $150{ }^{\circ} \mathrm{C}$ (OT04B), which was distinctly stronger and stiffer than the others (Fig. 6a). Z- and s-samples showed a slight gradual transition from brittle deformation at low temperature towards more ductile behavior with 
Table 4 Petrophysical parameters and mechanical data of samples deformed at $\dot{\varepsilon}$ $=5 \times 10^{-4} \mathrm{~s}^{-1}, T=100{ }^{\circ} \mathrm{C}$ and different confining pressures $p_{c}$

Table 5 Petrophysical

parameters and mechanical data of samples deformed at $\dot{\varepsilon}$ $=5 \times 10^{-4} \mathrm{~s}^{-1}, p_{c}=50 \mathrm{MPa}$ and different temperatures $T$

\begin{tabular}{llllllllll}
\hline Sample ID & $\begin{array}{l}\text { Sample } \\
\text { orienta- } \\
\text { tion }\end{array}$ & $\rho\left(\mathrm{g} / \mathrm{cm}^{3}\right)$ & $\varphi(\mathrm{vol} \%)$ & $p_{\mathrm{c}}(\mathrm{MPa})$ & $\sigma_{\max }(\mathrm{MPa})$ & $\varepsilon_{\max }(\%)$ & $E(\mathrm{GPa})$ & $B(-)$ & $\theta\left(^{\circ}\right)$ \\
& & & & & & & & & \\
\hline OT02 & $\mathrm{p}$ & 2.36 & 12.1 & 50 & 177 & 3.45 & 15.2 & 0.34 & 33 \\
OT01A & $\mathrm{p}$ & 2.37 & 12.9 & 75 & 193 & 5.16 & 12.7 & 0.29 & 35 \\
OT02A & $\mathrm{p}$ & 2.40 & 10.1 & 100 & 246 & 5.50 & 14.3 & 0.31 & 30 \\
OT05 & $\mathrm{z}$ & 2.36 & 13.3 & 50 & 142 & 4.17 & 7.6 & 0.45 & 47 \\
OT03A & $\mathrm{z}$ & 2.38 & 11.9 & 75 & 184 & 4.66 & 10.7 & 0.37 & 45 \\
OT06A & $\mathrm{z}$ & 2.36 & 12.8 & 100 & 185 & 6.13 & 8.6 & 0.35 & - \\
OT01 & $\mathrm{s}$ & 2.37 & 12.3 & 50 & 167 & 4.65 & 7.4 & 0.49 & 33 \\
OT04A & $\mathrm{s}$ & 2.37 & 12.6 & 75 & 179 & 4.62 & 9.3 & 0.42 & 37 \\
OT05A & $\mathrm{s}$ & 2.38 & 12.7 & 100 & 209 & 7.43 & 8.6 & 0.33 & - \\
\hline
\end{tabular}

$\rho$ density, $\varphi$ porosity, $\sigma_{\max }$ peak strength, $\varepsilon_{\max }$ strain at peak strength, $E$ Young's modulus, $B$ brittleness, $\theta$ angle between failure plane and loading direction,' two failure planes. $\mathrm{p}\left(0^{\circ}\right), \mathrm{z}\left(45^{\circ}\right)$ and $\mathrm{s}\left(90^{\circ}\right)$ represent the sample orientation between the loading direction relative to the bedding plane

\begin{tabular}{llllrlllll}
\hline Sample ID & $\begin{array}{l}\text { Sample } \\
\text { orienta- }\end{array}$ & $\rho\left(\mathrm{g} / \mathrm{cm}^{3}\right)$ & $\varphi(\mathrm{vol} \%)$ & $T\left({ }^{\circ} \mathrm{C}\right)$ & $\sigma_{\max }(\mathrm{MPa})$ & $\varepsilon_{\max }(\%)$ & $E(\mathrm{GPa})$ & $B(-)$ & $\theta\left(^{\circ}\right)$ \\
& tion & & & & & & & & \\
\hline OT08B & $\mathrm{p}$ & 2.38 & 12.1 & 25 & 177 & 3.11 & 15.3 & 0.37 & 28 \\
OT02B & $\mathrm{p}$ & 2.37 & 11.1 & 50 & 175 & 3.63 & 14.4 & 0.34 & 35 \\
OT02 & $\mathrm{p}$ & 2.36 & 12.1 & 100 & 177 & 3.45 & 15.2 & 0.34 & 33 \\
OT07B & $\mathrm{p}$ & 2.37 & 10.2 & 150 & 183 & 3.52 & 14.3 & 0.36 & 32 \\
OT04B & $\mathrm{p}$ & 2.44 & 7.7 & 150 & 215 & 1.95 & 25.3 & 0.44 & 25 \\
OT09B & $\mathrm{p}$ & 2.37 & 12.7 & 200 & 175 & 3.65 & 14.6 & 0.33 & 30 \\
OT11B & $\mathrm{z}$ & 2.37 & 12.4 & 25 & 157 & 3.58 & 9.8 & 0.45 & 41 \\
OT01B & $\mathrm{z}$ & 2.36 & 12.7 & 50 & 155 & 3.91 & 9.5 & 0.42 & $30^{*}$ \\
OT05 & $\mathrm{z}$ & 2.36 & 13.3 & 100 & 142 & 4.17 & 7.6 & 0.45 & 47 \\
OT06B & $\mathrm{z}$ & 2.39 & 11.2 & 150 & 140 & 3.65 & 9.3 & 0.42 & $32^{*}$ \\
OT10B & $\mathrm{z}$ & 2.37 & 11.8 & 200 & 152 & 2.98 & 10.8 & 0.47 & 33 \\
OT03B & $\mathrm{s}$ & 2.38 & 12.5 & 50 & 172 & 3.42 & 10.2 & 0.50 & 30 \\
OT01 & $\mathrm{s}$ & 2.37 & 12.3 & 100 & 167 & 4.65 & 7.4 & 0.49 & 33 \\
OT05B & $\mathrm{s}$ & 2.38 & 13.2 & 150 & 157 & 4.40 & 8.5 & 0.42 & 41 \\
OT12B & $\mathrm{s}$ & 2.35 & 13.5 & 200 & 177 & 3.82 & 10.9 & 0.42 & 33 \\
OT13B & $\mathrm{s}$ & 2.39 & 12.3 & 200 & 173 & 4.02 & 10.2 & 0.42 & 39 \\
\hline
\end{tabular}

$\rho$ density, $\varphi$ porosity, $T$ temperature, $\sigma_{\max }$ peak strength, $\varepsilon_{\max }$ strain at peak strength, $E$ Young's modulus, $B$ brittleness, $\theta$ angle between failure plane and loading direction,' two failure planes, * $\mathrm{z}$-sample with failure plane perpendicular to bedding. $\mathrm{p}\left(0^{\circ}\right), \mathrm{z}\left(45^{\circ}\right)$ and $\mathrm{s}\left(90^{\circ}\right)$ represent the sample orientation between the loading direction relative to the bedding plane minor post-failure weakening at high $T$ (Fig. 6b, c). Peak strength of $\mathrm{z}$ - and s-samples displayed a small decrease with increasing temperatures up to $150^{\circ} \mathrm{C}$ (Fig. 6d). Total strain at failure (Table 5), Young's moduli (Fig. 6e) and brittleness values (Fig. 6f) are independent of $T$.

\subsubsection{Effect of Strain Rate}

The effect of strain rate on the mechanical behavior of dried OPA was tested at strain rates between $\dot{\varepsilon}=1 \times 10^{-3}$ and $5 \times 10^{-6} \mathrm{~s}^{-1}$ at $p_{\mathrm{c}}=50 \mathrm{MPa}$ and $T=100{ }^{\circ} \mathrm{C}$. Stress-strain curves (Fig. 7a-c) showed only weak trends concerning the effect of strain rate on the deformation behavior of tested samples.

Irrespective of sample-to-sample variation, p-samples display a trend of decreasing peak strength with decreasing strain rate (Fig. 7d). One sample (OT07) tested at the lowest strain rate showed relatively high strength (Table 6). This sample was characterized by through-going sand-rich layers. Z-samples showed no clear effect of strain rate on strength. In contrast, s-samples displayed an almost linear increase of peak strength with decreasing strain rate. In most cases, the 

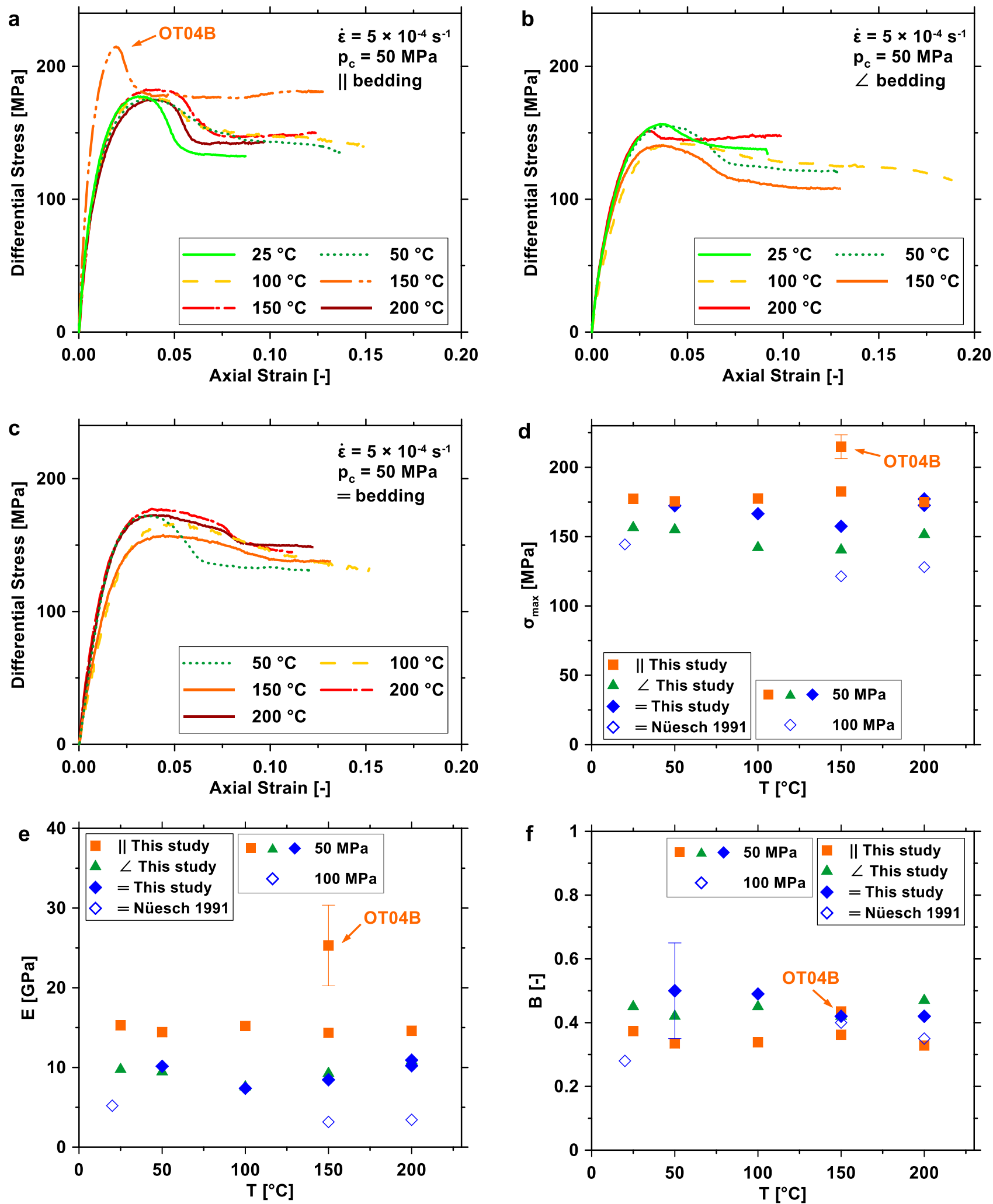

Fig. 6 Influence of temperature $T$ on stress-strain behavior of parallel (a), $45^{\circ}$ (b) and perpendicular (c) oriented samples of the sandy facies. The relation between temperature $T$ and peak strength $\sigma_{\max }$ (d), Young's modulus $E(\mathbf{e})$ as well as brittleness $B$ (f) of this study is

compared to the results of the shaly facies, tested at $p_{c}=100 \mathrm{MPa}$ and $\dot{\varepsilon}=8.4 \times 10^{-5}-8.8 \times 10^{-5} \mathrm{~s}^{-1}$ (Nüesch 1991) represented by open symbols. Deformation conditions and sample orientations are indicated 

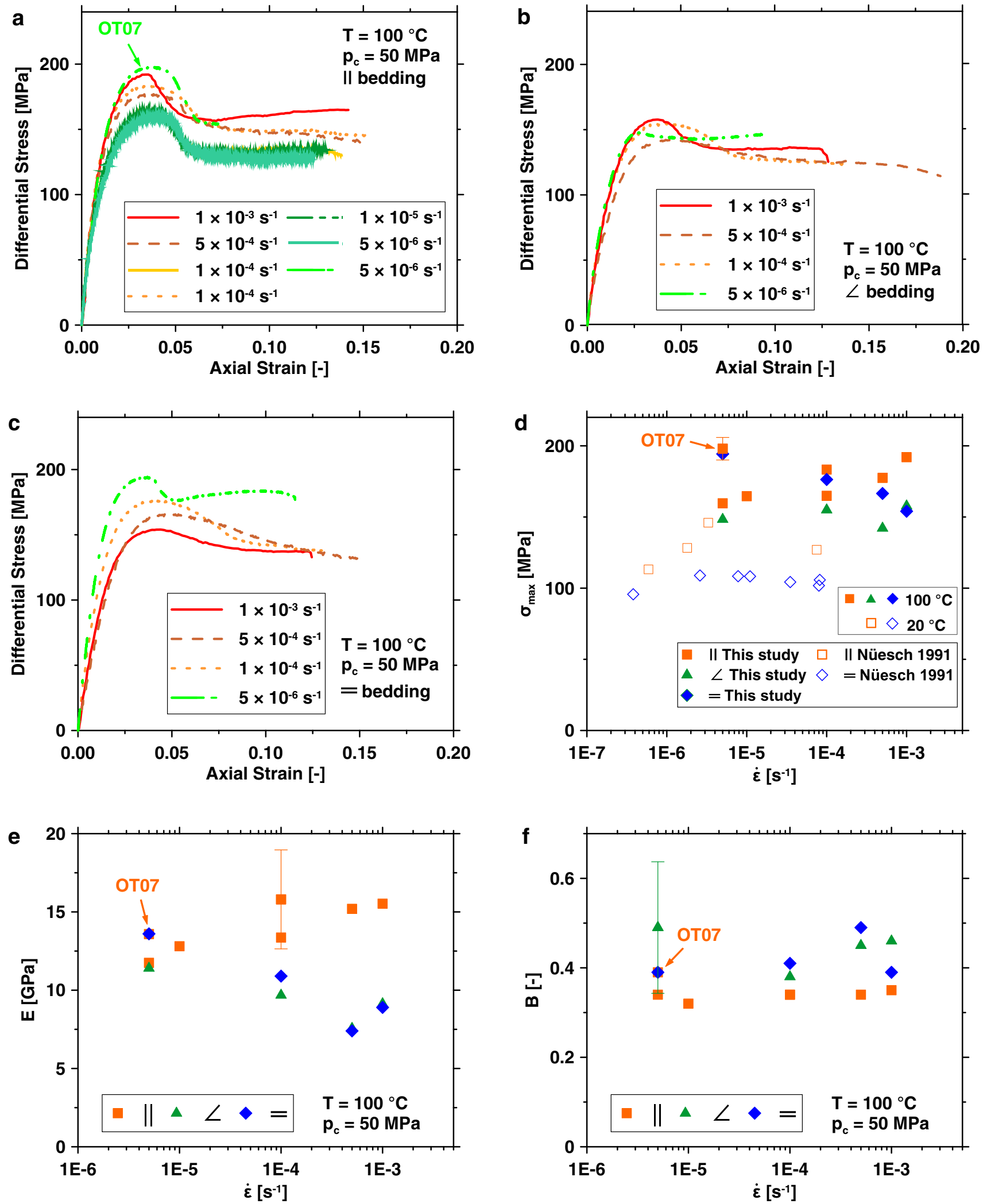

Fig. 7 Effect of strain rate $\dot{\varepsilon}$ on the mechanical behavior of samples loaded parallel (a), $45^{\circ}$ (b) and perpendicular (c) to bedding orientation. Influence of strain rate $\dot{\varepsilon}$ on the peak strength $\sigma_{\max }$ of the sandy facies (this study) in comparison to the results of the shaly facies (Nüesch 1991), represented by open symbols, both facies are tested

at $p_{c}=50 \mathrm{MPa}(\mathbf{d})$. Correlating strain rate $\dot{\varepsilon}$ vs. Young's modulus $E$ (e) reveal opposite behavior of strength for p- and s-samples, whereas strength of z-samples shows no correlation with strain rate. A clear relation between strain rate $\dot{\varepsilon}$ and brittleness $B$ was not found (f). Deformation conditions and sample orientations are indicated 
Table 6 Petrophysical parameters and mechanical data of samples deformed at $p_{c}=50 \mathrm{MPa}, T=100{ }^{\circ} \mathrm{C}$ and different strain rates $\dot{\varepsilon}$

\begin{tabular}{llllllllll}
\hline Sample ID & $\begin{array}{l}\text { Sample } \\
\text { orienta- }\end{array}$ & $\rho\left(\mathrm{g} / \mathrm{cm}^{3}\right)$ & $\varphi($ vol $\%)$ & $\dot{\varepsilon}\left(\mathrm{s}^{-1}\right)$ & $\sigma_{\max }(\mathrm{MPa})$ & $\varepsilon_{\max }(\%)$ & $E(\mathrm{GPa})$ & $B(-)$ & $\theta\left(^{\circ}\right)$ \\
& tion & & & & & & & & \\
\hline OT13 & $\mathrm{p}$ & 2.35 & 13.1 & $1 \times 10^{-3}$ & 192 & 3.56 & 15.5 & 0.35 & 31 \\
OT02 & $\mathrm{p}$ & 2.36 & 12.1 & $5 \times 10^{-4}$ & 177 & 3.45 & 15.2 & 0.34 & 33 \\
OT16 & $\mathrm{p}$ & 2.39 & 10.3 & $1 \times 10^{-4}$ & 183 & 3.44 & 15.8 & 0.34 & 29 \\
OT17 & $\mathrm{p}$ & 2.36 & 12.7 & $1 \times 10^{-4}$ & 165 & 3.58 & 13.4 & 0.34 & 32 \\
OT15 & $\mathrm{p}$ & 2.37 & 12.5 & $1 \times 10^{-5}$ & 165 & 4.03 & 12.8 & 0.32 & 31 \\
OT07 & $\mathrm{p}$ & 2.34 & 13.4 & $5 \times 10^{-6}$ & 198 & 3.76 & 13.6 & 0.39 & 30 \\
OT14 & $\mathrm{p}$ & 2.36 & 12.7 & $5 \times 10^{-6}$ & 160 & 3.99 & 11.8 & 0.34 & 31 \\
OT19 & $\mathrm{z}$ & 2.36 & 12.9 & $1 \times 10^{-3}$ & 158 & 3.76 & 9.1 & 0.46 & 37 \\
OT05 & $\mathrm{z}$ & 2.36 & 13.3 & $5 \times 10^{-4}$ & 142 & 4.17 & 7.6 & 0.45 & 47 \\
OT18 & $\mathrm{z}$ & 2.36 & 13.0 & $1 \times 10^{-4}$ & 155 & 4.18 & 9.7 & 0.38 & $31^{*}$ \\
OT10 & $\mathrm{z}$ & 2.36 & 13.2 & $5 \times 10^{-6}$ & 148 & 2.68 & 11.4 & 0.49 & 41 \\
OT23 & $\mathrm{s}$ & 2.37 & 13.0 & $1 \times 10^{-3}$ & 154 & 4.39 & 8.9 & 0.39 & 43 \\
OT01 & $\mathrm{s}$ & 2.37 & 12.3 & $5 \times 10^{-4}$ & 167 & 4.65 & 7.4 & 0.49 & 33 \\
OT26 & $\mathrm{s}$ & 2.35 & 13.3 & $1 \times 10^{-4}$ & 176 & 3.95 & 10.9 & 0.41 & 35 \\
OT22 & $\mathrm{s}$ & 2.41 & 11.2 & $5 \times 10^{-6}$ & 194 & 3.71 & 13.6 & 0.39 & 33 \\
\hline
\end{tabular}

$\rho$ density, $\varphi$ porosity, $\dot{\varepsilon}$ strain rate, $\sigma_{\max }$ peak strength, $\varepsilon_{\max }$ strain at peak strength, $E$ Young's modulus, $B$ brittleness, $\theta$ angle between failure plane and loading direction,' two failure planes, ${ }^{*} \mathrm{z}$-sample with failure plane perpendicular to bedding. $\mathrm{p}\left(0^{\circ}\right), \mathrm{z}\left(45^{\circ}\right)$ and $\mathrm{s}\left(90^{\circ}\right)$ represent the sample orientation between the loading direction relative to the bedding plane shape of stress-strain curves, in particular post-peak strain weakening, was not systematically affected by the applied strain rate. Notably, strain at peak strength and yield point of p-samples decreased slightly with increasing strain rate. For z- and s-samples, axial strain at peak and yield stress decreased with decreasing strain rate.

Young's moduli of p-samples decreased with decreasing strain rate, in contrast to s- and z-samples for which Young's modulus decreased with increasing strain rate (Fig. 7e). However, brittleness of all samples was not affected by applied strain rate (Fig. 7f).

\subsubsection{Effect of Water Content}

To investigate the influence of water content on the mechanical behavior of OPA, we deformed saturated samples $\left(S_{w}=96.1 \pm 1.3 \%\right)$ at $p_{\mathrm{c}}=50 \mathrm{MPa}, T=100{ }^{\circ} \mathrm{C}$ and strain rates of $\dot{\varepsilon}=5 \times 10^{-4} \mathrm{~s}^{-1}$ and $5 \times 10^{-6} \mathrm{~s}^{-1}$ at undrained conditions (Table 7). Compared to dry samples, saturated samples show strongly reduced strength, depending on sample orientation (Fig. 8). At high strain rate $\left(\dot{\varepsilon}=5 \times 10^{-4} \mathrm{~s}^{-1}\right)$, peak strength of s- and z-samples is reduced by $41 \%$ and $48 \%$, respectively, whereas the peak strength of parallel oriented p-samples is reduced by $27 \%$ (Table 7). Strain at peak strength is quite

Table 7 Petrophysical parameters and mechanical data of samples deformed at $p_{c}=50 \mathrm{MPa}, T=100{ }^{\circ} \mathrm{C}$ and different strain rates $\dot{\varepsilon}$ as well as saturation degree $S_{v}$

\begin{tabular}{llllllllrrr}
\hline Sample ID & $\begin{array}{l}\text { Sample } \\
\text { orientation }\end{array}$ & $S_{w}(\%)$ & $\rho\left(\mathrm{g} / \mathrm{cm}^{3}\right)$ & $\varphi(\mathrm{vol} \%)$ & $\dot{\varepsilon}\left(\mathrm{s}^{-1}\right)$ & $\sigma_{\max }(\mathrm{MPa})$ & $\varepsilon_{\max }(\%)$ & $E(\mathrm{GPa})$ & $B(-)$ & $\theta\left(^{\circ}\right)$ \\
\hline OT02 & $\mathrm{p}$ & dry & 2.36 & 12.1 & $5 \times 10^{-4}$ & 177 & 3.45 & 15.2 & 0.34 & 33 \\
OT04 & $\mathrm{p}$ & 97.9 & 2.46 & $13.8^{*}$ & $5 \times 10^{-4}$ & 130 & 3.64 & 10.1 & 0.35 & $30^{\prime}$ \\
OT05 & $\mathrm{z}$ & dry & 2.36 & 13.3 & $5 \times 10^{-4}$ & 142 & 4.17 & 7.6 & 0.45 & 47 \\
OT025 & $\mathrm{z}$ & 95.2 & 2.46 & $13.8^{*}$ & $5 \times 10^{-4}$ & 74 & 2.50 & 8.8 & 0.34 & 38 \\
OT01 & $\mathrm{s}$ & dry & 2.37 & 12.3 & $5 \times 10^{-4}$ & 167 & 4.65 & 7.4 & 0.49 & 33 \\
OT03 & $\mathrm{s}$ & 97.5 & 2.47 & $14.0^{*}$ & $5 \times 10^{-4}$ & 98 & 5.31 & 5.8 & 0.32 \\
OT22 & $\mathrm{s}$ & dry & 2.41 & 11.2 & $5 \times 10^{-6}$ & 194 & 3.71 & 13.6 & 0.39 & 33 \\
OT09 & $\mathrm{s}$ & 94.6 & 2.45 & $13.1^{*}$ & $5 \times 10^{-6}$ & 126 & 4.09 & 7.3 & 0.43 & 39 \\
\hline
\end{tabular}

$\rho$ density, $\varphi$ porosity, $\sigma_{\max }$ peak strength, $\varepsilon_{\max }$ strain at peak strength, $E$ Young's modulus, $B$ brittleness, $\theta$ angle between failure plane and loading direction,' two failure planes, $S_{w}$ degree of saturation. $\mathrm{p}\left(0^{\circ}\right), \mathrm{z}\left(45^{\circ}\right)$ and $\mathrm{s}\left(90^{\circ}\right)$ represent the sample orientation between the loading direction relative to the bedding plane. $*$ determined from sub-samples after drying at $110^{\circ} \mathrm{C}$ 

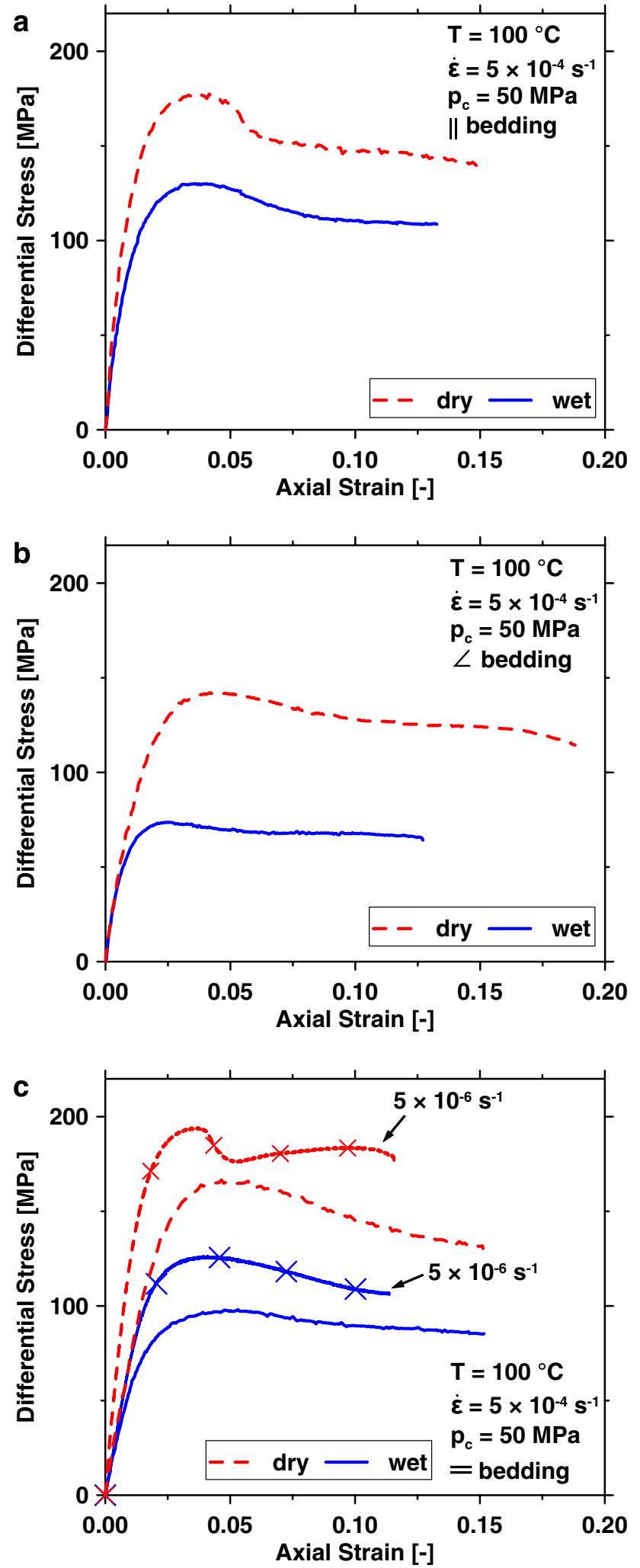

Fig. 8 Effect of saturation on the mechanical response of parallel (a), $45^{\circ}$ (b) and perpendicular (c) oriented samples at different strain rates. Deformation conditions and sample orientations are indicated similar for dry and saturated p- and s-samples, whereas saturated z-samples show a reduction of about $40 \%$ compared to dry samples. The difference in strength between samples prepared with different bedding orientations is larger for saturated samples compared to dry specimens. S-samples were additionally deformed at a strain rate of $\dot{\varepsilon}=5 \times 10^{-6} \mathrm{~s}^{-1}$ revealing a peak strength reduction for saturated samples of $35 \%$. Interestingly, for both dry and saturated samples, peak strength was higher at $\dot{\varepsilon}=5 \times 10^{-6} \mathrm{~s}^{-1}$ compared to $\dot{\varepsilon}$ $=5 \times 10^{-4} \mathrm{~s}^{-1}$ (Fig. 8c).

For p- and s-samples, the Young's modulus decreased with increasing water saturation but remained constant within error bars for z-samples. In contrast, brittleness shows no clear correlation with sample saturation (Table 7).

\subsection{Deformation Structures}

\subsubsection{Macrofabrics of Deformed Samples}

Macroscopic observation of the deformed samples revealed localized, narrow (0.25-1 mm) shear zones and/or distributed deformation, depending on applied confining pressure conditions and loading direction with respect to bedding orientation (Figs. 9 and 10). Neither temperature nor strain rate affected strain localization, shear zone orientation and deformation regime. Shape, width and orientation of localized shear zones depend on compositional heterogeneity and anisotropy of the undeformed sample.

Cross sections prepared normal to the macroscopic shear plane show that $\mathrm{p}$-samples exhibit formation of one or two shear fractures oriented $28-35^{\circ}$ to the loading direction. Single shear fractures often occur in samples dominated by quartz-rich layers. These samples disintegrated along the shear plane after they were removed from the copper jacket. In some cases, shear plane orientation changes locally or is offset, reminiscent of kink-bands (Figs. 9b, 10a white arrow). Some samples show kink bands leading to formation of two parallel fractures with increasing strain (Table 3-7, Figs. 9c, 10b). Within the kink-bands, clay-rich layers rotate between $50^{\circ}$ and $80^{\circ}$ relative to the original bedding orientation (Fig. 10a black arrow, Fig. 10b white arrow). Shear zone boundaries and discrete fractures in p-samples always develop sub-parallel to bedding direction and crosscut compositional layering. Single shear zones tend to widen, offset and branch in quartz-rich layers and are narrow in clay-rich zones (white half-arrows in Fig. 10a).

In z-samples, shear zones formed at $30^{\circ}-50^{\circ}$ to the sample axis, which are predominantly localized in clay-rich layers (Fig. 9f-h). Shear zones formed mostly sub-parallel to bedding orientation, rarely perpendicular to bedding (Tables 5, 6). For example, stress-strain curves of z-samples tested at $50{ }^{\circ} \mathrm{C}$ and $150{ }^{\circ} \mathrm{C}$ show pronounced postpeak strain weakening, associated with the formation of a 
macroscopic shear zone oriented perpendicular to bedding (Fig. 6). In general, the orientation of shear zones in z-samples changes depending on compositional layering (white arrows in Fig. 9f, h). Macroscopically shear zones are thin $(<0.75 \mathrm{~mm})$ and often difficult to identify with highly localized shear displacement (Fig. 10c, white arrow). The width of shear zones increased at high pressure $\left(p_{\mathrm{c}} \geq 75 \mathrm{MPa}\right)$ and with increasing initial thickness of clay-rich layers in the undeformed sample. At $100 \mathrm{MPa}$ confining pressure, z-samples exhibit almost homogeneous shortening with some minor shear zones (Fig. 9h, white arrowheads).

Single shear bands that are aligned between $30^{\circ}$ and $49^{\circ}$ to the loading axis are developed in s-samples (Fig. $9 \mathrm{j}-1$ ). The amount and spatial distribution of clay-rich layers affect strain localization and shear plane orientation. Samples that contain high amounts of large quartz-rich seams display narrow and steeply inclined $(\theta)$ shear zones (Fig. 9j). In contrast, shear zones are wider in clay-rich parts (Fig. 10d, e white arrows). Additionally, specimens that contain individual clay-rich layers of several millimeter widths, display bulging (Fig. 9k, black arrow). Strain is localized in narrow shear zones showing changing inclination at compositional boundaries (Fig. 10e, black arrow). At a confining pressure of $p_{\mathrm{c}}=100 \mathrm{MPa}$, deformation is distributed within clay-rich layers (Fig. 91, white arrow).

Macroscopically, strain is localized in clay-rich layers in deformed s- and z-samples, whereas continuous quartz-rich layers remain unaffected (upper sample half in Fig. 9f, g and $\mathrm{j}-\mathrm{l})$.

Macroscopic deformation structures of saturated samples are similar to those of dry samples tested at similar conditions. However, saturated samples (Fig. 9d) display branching of shear zone networks and increasing shear zone width in s- and p-samples.

\subsubsection{Microstructures of Deformed Samples}

Deformation microstructures of selected samples containing shear zones were examined by SEM, using BIB-polished cross sections, prepared perpendicular to $\sigma_{I}$-direction. Two to three areas were polished per sample to image a macroscopic visible shear zone in which strain localized as well as sections several millimeters apart from the shear zone. Deformed samples show a combination of brittle (microfracturing, frictional sliding, grain rotation) and crystal plastic (bending and kinking of phyllosilicates) deformation processes at the tested experimental conditions (Fig. 11).

The shear zones observed in $\mathrm{p}$ - and s-samples are characterized by shape-preferred orientation of non-clay minerals and clay matrix. Clay minerals display a sigmoidal alignment in the sense of shear at an angle of about 40 and $60^{\circ}$ to bedding for s- and p-samples, respectively (Fig. 11a, c). Shear zones may be recognized by rotation of fractured grains (Fig. 11c point 1) and bending of micas and clay minerals (dotted line Fig. 11a, c), indicating a gradual fabric transition between shear zone and wall rock (dotted line in Fig. 11a, c). Strain in the shear zone of p-samples is heterogeneously distributed (Fig. 11a). Clastic mineral grains are often fractured and aligned, showing different degrees of fragmentation ranging from single fractures and trails of comminuted quartz (Fig. 11a points 6 and 9) up to almost fully disintegrated calcite (Fig. 11a point 5) reworked within the shear zone. Within the damage zone, clastic grains are highly comminuted, with angular grain fragments and particle sizes less than $1 \mu \mathrm{m}$. Trails of crushed grains (e.g., former framboidal pyrite in Fig. 11a point 1, Fig. 11c point 5) formed oblique to the shear direction, indicating sigmoidal P-foliation (Rutter et al. 1986). In shear zones of s-samples, we also find rotation of fractured grains (Fig. 11c points 2, 5 and 6) and organic matter (Fig. 11c point 3) aligning parallel to P-foliation as well as the development of an S-C fabric (Logan et al. 1979), as shown by the dash-dotted line in Fig. 11c. A network of lens-shaped clusters was found, which are separated by anastomosing open fractures possibly due to unloading (Fig. 11d point 5). The clusters are of varying size, show almost no visible porosity, and display $\mu \mathrm{m}$-thin sheared boundaries with individual nanometer-sized clay particles aligned parallel to the local shear direction, indicating clay particle sliding. Especially calcite (Fig. 11a point 7) and feldspar (Fig. 11a point 8) grains preferentially fracture along cleavages displaying mosaic fragmentation. In shear zones of s- and z-samples, grain fragments are offset indicating slip parallel to the shear direction. In samples oriented $45^{\circ}$ to bedding, clay particles are strongly aligned parallel to the shear direction (Fig. 11d point 4). Clasts are rotated parallel to bedding and are surrounded by microshear zones formed by the clay matrix that are also indicated by strong delamination and kinking of micas (Fig. 11d point 5). As observed macroscopically, strain localized at the boundary of sand layers and lenses in the clay matrix of s- and z-samples. Depending on the degree of comminution and reworking into the clay matrix, fractured quartz grains display increased interparticle porosity (Fig. 11a points 2 and 3). Domino-like boudins of fractured grains, cracks oriented sub-parallel to $\sigma_{l}$-direction with asymmetric apertures (Fig. 11d point 1), and intrusion of clay matrix into open fractures (Fig. 11d point 3, Fig. 11e point 1) indicate a process of episodic fracturing and rotation of non-clay minerals (Fig. 11d point 2, Fig. 11e point 2).

In sand lenses outside the shear zone, clastic minerals are frequently inter- and intragranular fractured without visible offsets and matching grain boundaries of single fragments (Fig. 11b points 2, 3 and 4). Impingement cracks are predominantly generated at the tip of single grains touching each other, suggesting stress concentration. Fractures are often open with apertures up to several micrometers 

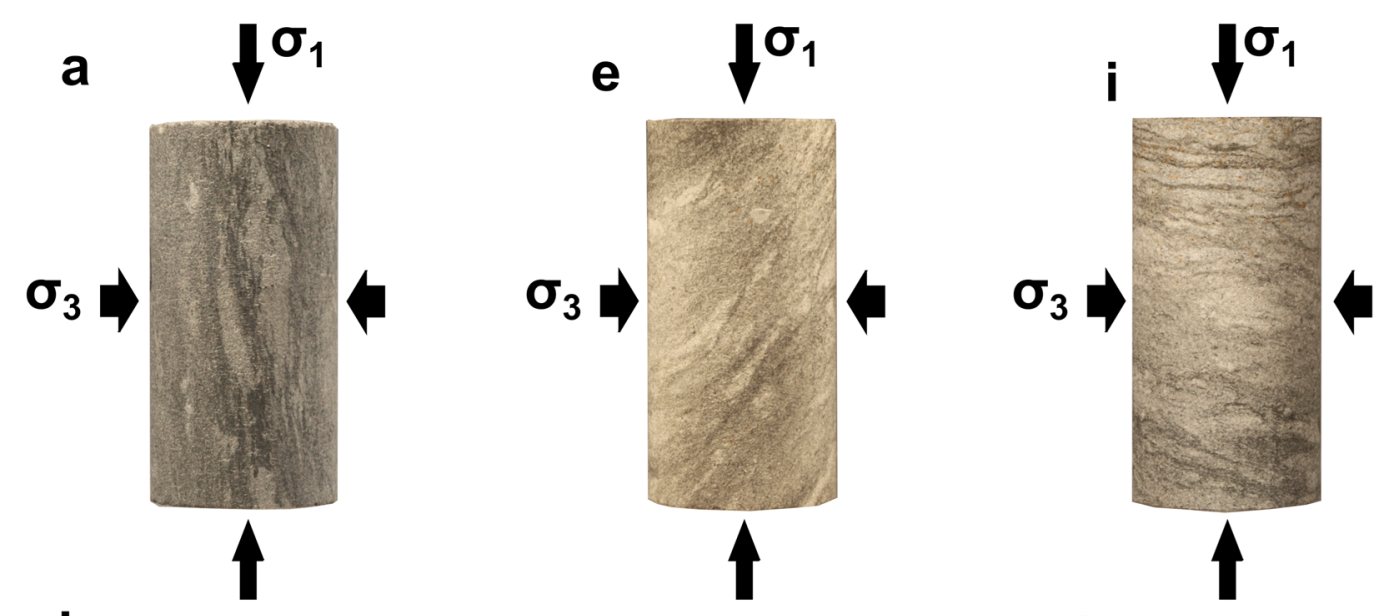

b

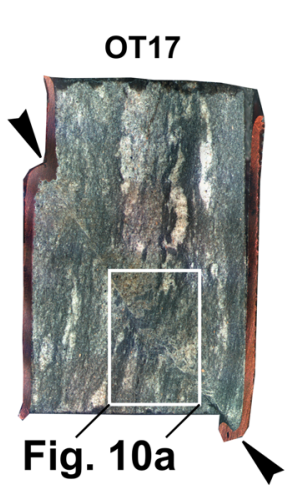

f

j
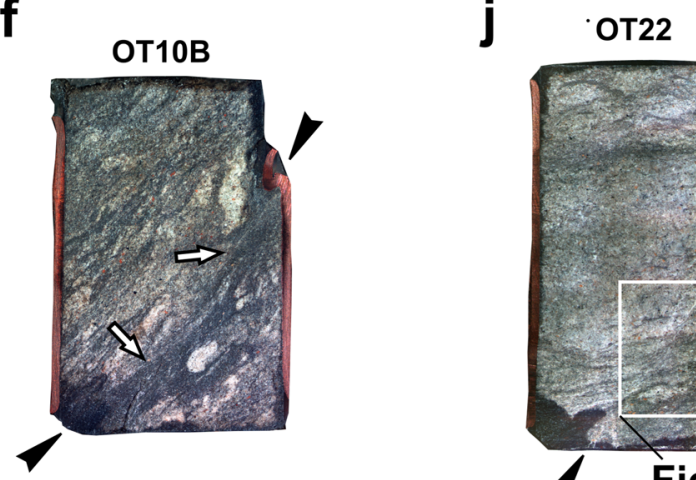

C

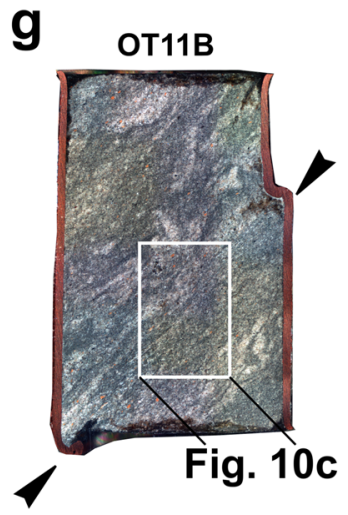

d
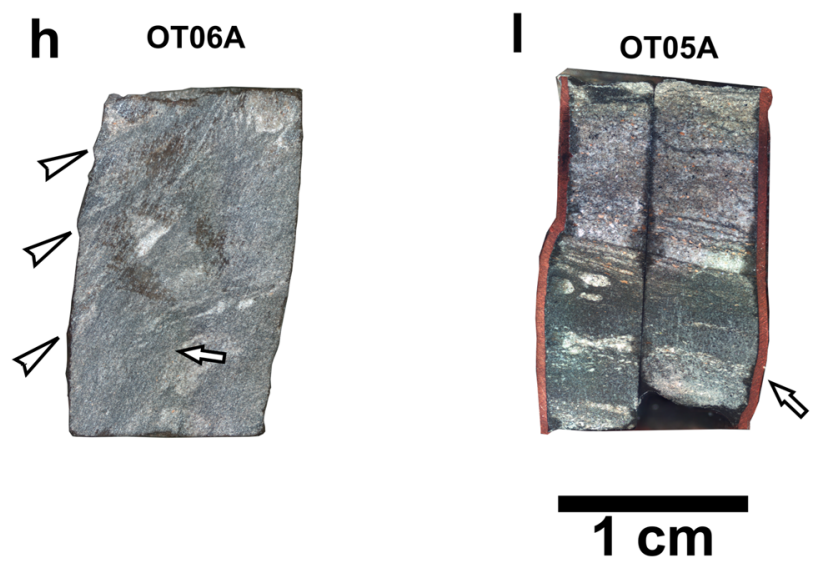
४Fig. 9 Top row: Photographs of undeformed samples of the sandy facies Opalinus Clay prepared parallel (a), $45^{\circ}$ (e) and perpendicular (i) to bedding. Below: Reflected light micrographs show deformation features of samples compressed parallel (b-d), $45^{\circ}(\mathbf{f}-\mathbf{h})$ and perpendicular $(\mathbf{j}-\mathbf{l})$ to bedding. At constant $p_{c}=50 \mathrm{MPa}, T=100{ }^{\circ} \mathrm{C}$ samples OT17 $\left(1 \times 10^{-4} \mathrm{~s}^{-1}\right)$ and OT22 $\left(5 \times 10^{-6} \mathrm{~s}^{-1}\right)$ were deformed at varied strain rates $\dot{\varepsilon}$. Samples OT09B $\left(200{ }^{\circ} \mathrm{C}\right)$, OT11B $\left(25^{\circ} \mathrm{C}\right)$, OT10B $\left(200{ }^{\circ} \mathrm{C}\right)$ and OT13B $\left(200{ }^{\circ} \mathrm{C}\right)$ were deformed at different temperatures $T$ but constant $p_{c}=50 \mathrm{MPa}$ and $\dot{\varepsilon}=5 \times 10^{-4} \mathrm{~s}^{-1}$. OT04A and OT05A were deformed at $p_{c}=100 \mathrm{MPa}, T=100{ }^{\circ} \mathrm{C}$ and $\dot{\varepsilon}=5 \times 10^{-4} \mathrm{~s}^{-1}$. OT04 was saturated to $S_{w}=97.9 \%$ and deformed at $p_{c}=50 \mathrm{MPa}, T=100{ }^{\circ} \mathrm{C}$ and $\dot{\varepsilon}=5 \times 10^{-4} \mathrm{~s}^{-1}$ Angular deviations along the shear surfaces are indicated by the asymmetrical plunge of black arrowheads, locating the traces of discrete and distributed (white) shear zones. The vertical crack in sample OT05A (I) is due to preparation. The areas marked by white frames are shown in detail in Fig. 10. See text for details, indicated by black and white arrows

sub-parallel to the maximum stress direction, indicating Mode I fracturing. Intergranular fractured calcite and quartz grains are highly abundant in sandy layers of samples oriented parallel to bedding (Fig. 11b point 3 ) but less prominent in s- and z-samples. The clay matrix, filling the space between grain-supported mineral clasts, shows almost no deformation (Fig. $11 \mathrm{~b}$ point 1 ).

Isolated grains embedded in the clay matrix show a shape-preferred orientation along the bedding direction and seldom display cracks sub-parallel to the $\sigma_{1}$-direction. Particles of organic matter as well as framboidal pyrite are bent and elongated. Depending on their orientation relative to the loading direction, micas are locally delaminated along the (001) basal plane, and strongly bent and kinked (Fig. 11a point 4, Fig. 11c point 4). With increasing bulk strain, kinked micas become fractured or boudinaged, creating voids. Pore collapse within the matrix is indicated by highly compacted clay particles generally aligned parallel to bedding. However, clay platelets in the vicinity of mineral clasts strongly arrange around local grain boundaries by microfolding, kinking and bending (Fig. 11b dotted line). As observed in undeformed material, the clay matrix is heterogeneously compacted with high strain localization and the occurrence of nanometer-sized clay particles at bottlenecks between single non-clay mineral grains (Fig. 11e point 3 ).

Microstructures of water-saturated samples were similar to dry samples tested at similar conditions. However, shear zone boundaries in p- and s-samples as well as foliation within the shear zone are more pronounced at high saturation.

\section{Discussion}

The sandy facies of Opalinus Clay displays brittle to semibrittle deformation characteristics (Evans and Kohlstedt 1995) at the applied experimental conditions of confining pressure, temperature, strain rate and water saturation. The samples were deformed by a combination of distributed brittle (microfracturing, particle sliding) and crystal plastic (bending, kinking) mechanisms. Stress-strain curves showed non-linear strain hardening until peak stress, followed by post-peak strain weakening turning into stable sliding at constant stress. Strength strongly increased with applied confining pressure. Measured strength and Young's modulus revealed minor temperature and strain rate sensitivity that is expected if crystal plastic deformation and/or stress corrosion are not the dominant deformation mechanisms. Sample strength was strongly affected by water content and the angle between loading direction and bedding plane orientation at all tested conditions, which is in good agreement with results reported for the shaly facies of Opalinus Clay (e.g., Nüesch 1991; Naumann et al. 2007; Popp and Salzer 2007; Jaeggi et al. 2014). Due to the strong heterogeneity of the sample material, the pre-existing fabric of individual samples also affected the deformation behavior. We observed increased brittle behavior and strength for extreme low porous samples (e.g., OT04B) and samples that are dominated by quartz-rich sand layers cross-cutting the entire specimen (e.g., OT07). In the following, we discuss the influence of loading conditions with respect to bedding orientation, rock composition and initial fabric conditions on the mechanical response.

\subsection{Anisotropic Deformation Behavior}

\subsubsection{Deformation Mechanisms and Structural Development at Microscale}

The distribution of clay- and quartz-rich layers in sandy facies OPA and the orientation of loading direction to bedding control the partitioning between different deformation processes accommodating sample deformation. These comprise cataclastic flow involving microcracking and particle sliding of clastic grains, granular flow including frictional sliding of clay and non-clay particles (Paterson and Wong 2005), and crystal plasticity resulting in bent and kinked phyllosilicates presumably initiated by dislocation glide (e.g., Kronenberg et al. 1990; Ibanez and Kronenberg 1993). The micro-mechanisms control macroscopic deformation behavior and formation of shear zones. Independent of the deformation conditions and for all sample orientations, we observed brittle deformation processes like inter- and intragranular cracking, grain comminution, particle sliding and rotation at microscale, accommodating localized or distributed deformation by enhanced cataclastic or granular flow respectively (e.g., OT06A).

Young's moduli measured for samples loaded parallel to bedding are high compared to other orientations (Fig. 5b). This is likely due to a load-bearing framework formed by axially oriented quartz-rich layers (Sone and Zoback 2013). Various microcracks outside the shear zone (Fig. 11b) 
a

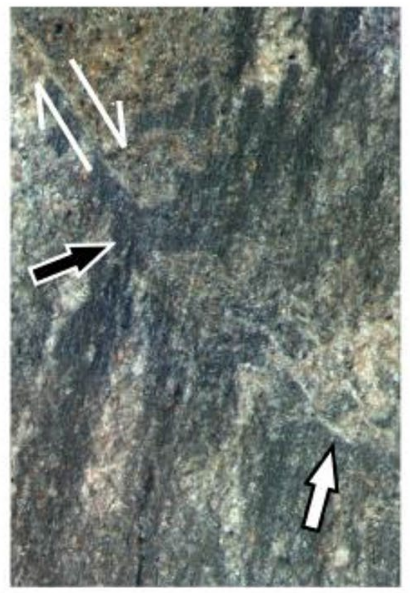

b

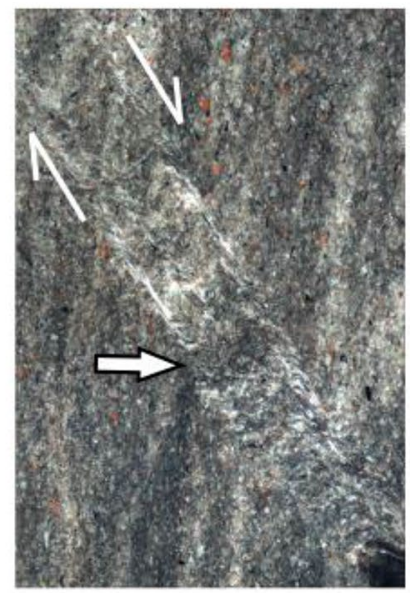

\section{C}

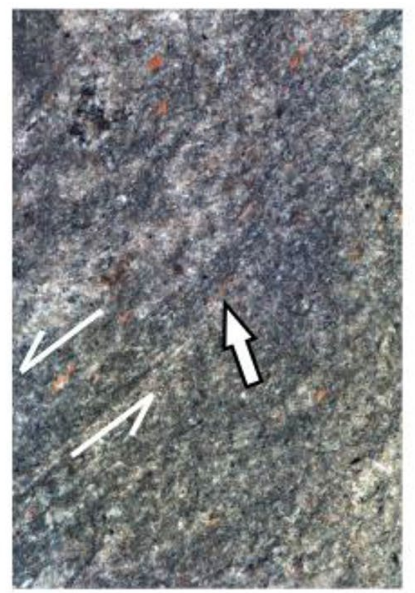

d

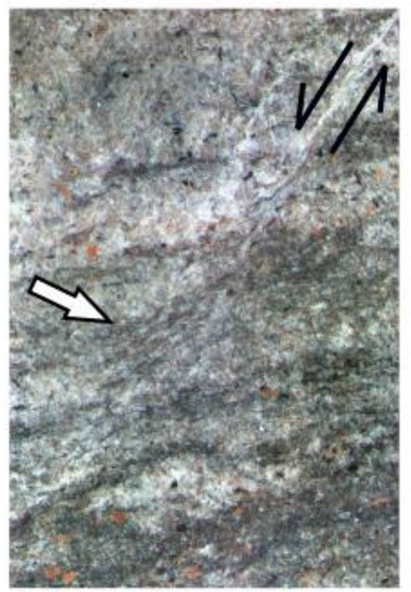

e

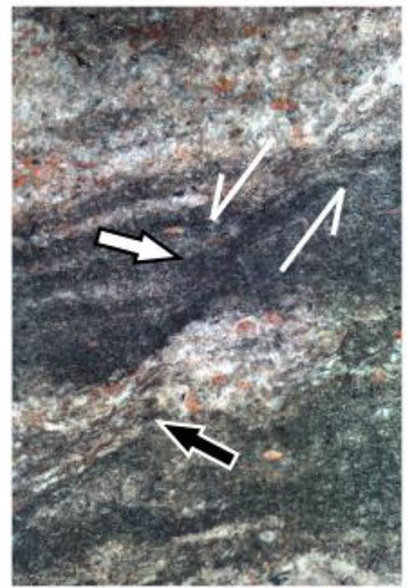

\section{$1 \mathrm{~mm}$}

shear zones as well as the sense of shear. See text for details, indicated by black and white arrows

granular flow with particle sliding of aligned clay aggregates and clastic particles controls strain weakening.

Comparable mechanisms as observed in s-samples are expected to act during the deformation of $\mathrm{z}$-samples. For samples in this orientation we found the lowest peak strength (Fig. 5a). This may be explained by the high shear stress resolved on the basal planes (001) of phyllosilicates. These are mainly oriented at $45^{\circ}$ to the loading direction, which enables deformation processes like delamination, basal slip and frictional sliding of phyllosilicates at lower stress than presumably needed for the fracturing of clastic grains (e.g., Kronenberg et al. 1990; Mares and Kronenberg 1993). The shear bands observed in z- and s-samples are in agreement with the observed microstructures, revealing preferred localization in clay-rich zones.

The deformation mechanisms observed in our samples are in agreement with the mechanisms observed in other 

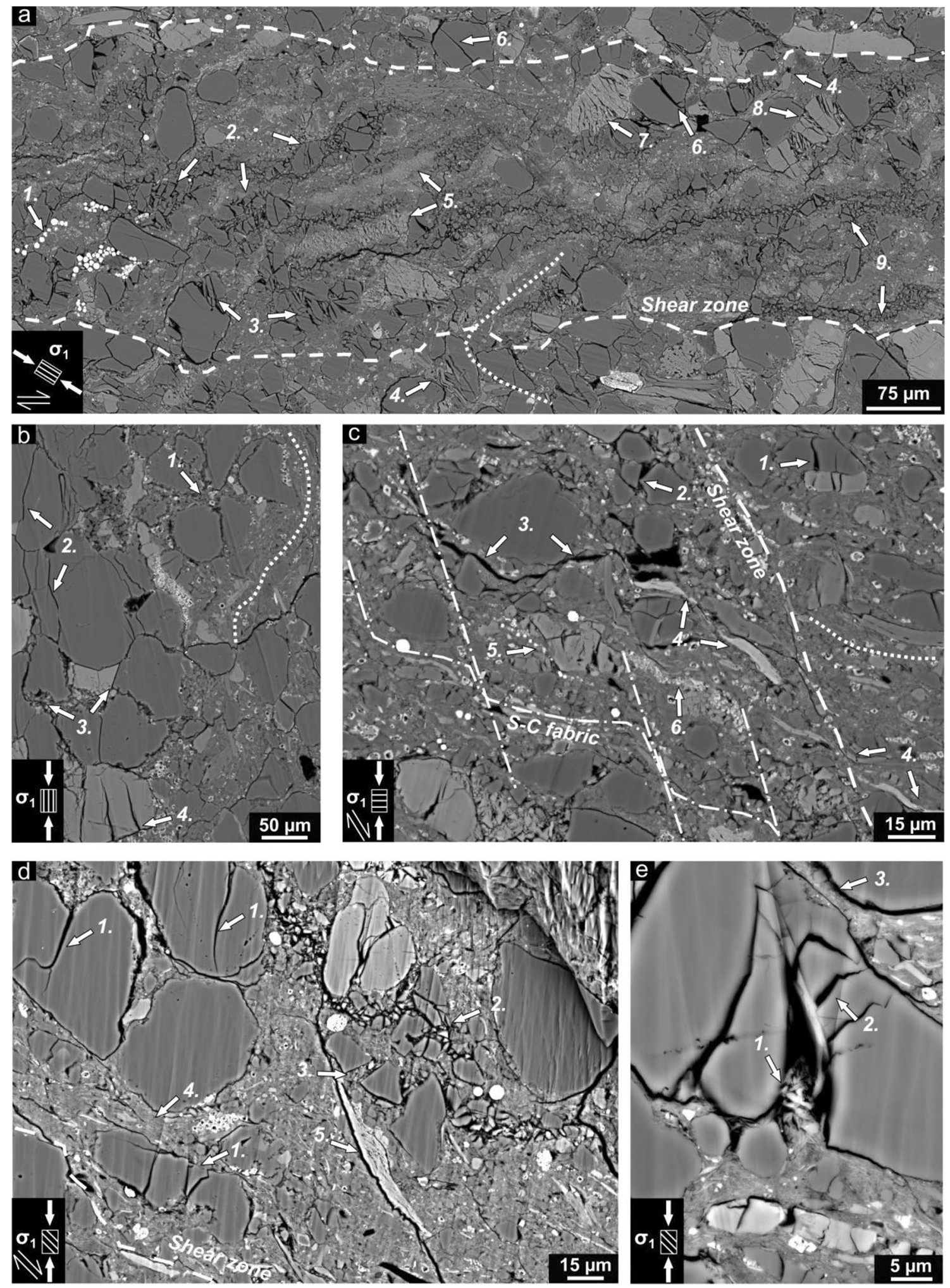

Fig. 11 Opalinus Clay of the sandy facies deformed at $p_{c}=50 \mathrm{MPa}$, $\dot{\varepsilon}=5 \times 10^{-4} \mathrm{~s}^{-1}$ and $T=100{ }^{\circ} \mathrm{C}$ parallel $(\mathbf{a}-\mathbf{b})$, perpendicular $(\mathbf{c})$ and $45^{\circ}(\mathbf{d}-\mathbf{e})$ to bedding direction. Shear and loading direction are indicated in the black boxes at the bottom left of each picture. Shear zone boundaries are indicated by dashed lines $(\mathbf{a}, \mathbf{c}, \mathbf{d})$. Dotted lines repre- sent shape-preferred orientation of clay particles around clastic grains outside the shear zone (b) or the gradual fabric transition between shear zone and wall rock (a, c). Further details labeled by numbers can be found in the text (chapter 3.2.2) 
laboratory studies conducted on Opalinus Clay. For the shaly facies, Nüesch (1991) concluded that strain localizes mainly by cataclastic flow accompanied by shearing and kinking of clay minerals, which is in agreement with the results obtained by Amann et al. (2012), Kaufhold et al. (2016), Desbois et al. (2018) and Orellana et al. (2018) for the shaly and the sandy facies Opalinus Clay. This suggests that Opalinus Clay deforms by brittle cataclastic flow under ambient and elevated pressure conditions ( $<400 \mathrm{MPa})$. However, in deformed shaly facies samples, micro-fracturing was rarely found to be intragranular and was dominant within shear zones. Matrix deformation was induced by pore compaction and granular flow. Microstructures inferred from experiments suggesting microcracking, intracrystalline plasticity of phyllosilicates and particle sliding are similar as observed in naturally deformed Opalinus Clay (Laurich et al. 2014, 2017, 2018). However, naturally generated gouge also shows evidence of pressure solution-precipitation and clay formation processes that are not captured under laboratory conditions, likely because these processes are too slow at experimental conditions (Laurich et al. 2014).

\subsubsection{Damage Initiation, Failure and the Influence of Confining Pressure}

The observed increase of strength with increasing confining pressure (Fig. 4d) is typical for dilatant brittle deformation. However, deformation of the sandy facies OPA is marked by non-linear strain hardening, which indicates that the initiation of damage and thus the accommodation of non-reversible strain is initiated before the peak stress is

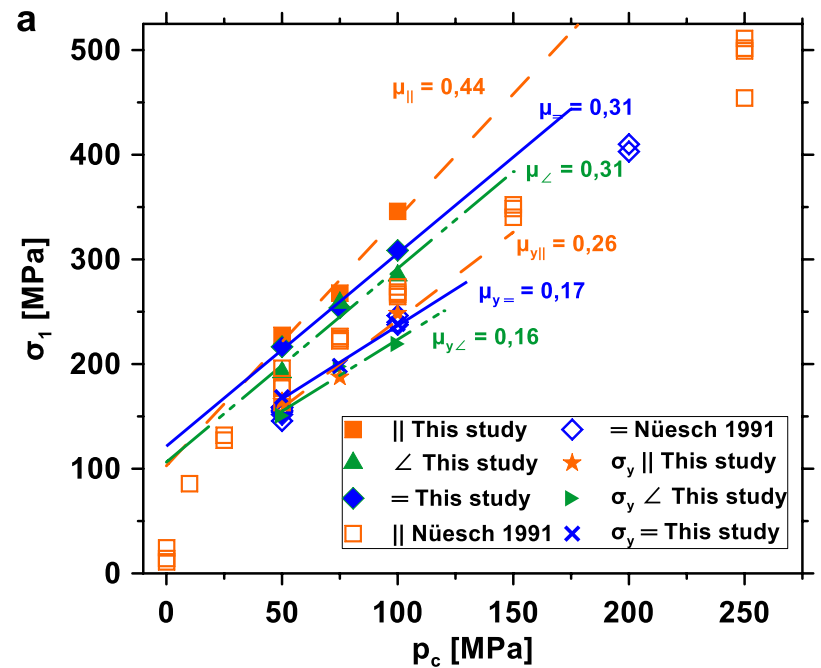

Fig. 12 Influence of confining pressure $p_{c}$ on axial peak strength and axial stress at the deviation from linearity $\left(\sigma_{y}\right)$ (a) of the sandy facies of Opalinus Clay (this study) tested at $T=100{ }^{\circ} \mathrm{C}$ and $\dot{\varepsilon}=5 \times 10^{-4} \mathrm{~s}^{-1}$ (solid symbols) in comparison to the axial peak strength of the shaly facies obtained at $T=20{ }^{\circ} \mathrm{C}$ and $\dot{\varepsilon}=1.3 \times 10^{-7}-8.4 \times 10^{-5} \mathrm{~s}^{-1}$ reached (e.g., Popp and Salzer 2007; Amann et al. 2012). We assume that the yield stress, determined at the onset of non-linearity of stress-strain curves, is equal to the stress at which damage initiates (e.g., Dresen and Evans 1993). Within the range of $50 \mathrm{MPa} \leq p_{c} \leq 100 \mathrm{MPa}$ the axial yield stress $\sigma_{y}$ of our experiments performed on dry rocks, reveals an almost linear increase with increasing confining pressure $p_{c}$ (Fig. 12a). We applied least square fitting to obtain the best fit slope constant $n$ that relates $\sigma_{y}$ and confining pressure $p_{c}$ to calculate the friction coefficients at yield $\mu_{y}$ for each orientation with the expression $\mu_{y}=(n-1) /(2 \sqrt{n})$ (Zoback 2007). Resulting values are between 0.16 and 0.26 (Table 8 ). Furthermore, peak strengths of the same samples were fitted to a linear Mohr-Coulomb failure criterion, expressed as $\tau=\tau_{0}+\mu \sigma_{n}$ or $\sigma_{1}=\sigma_{U C S}+n p_{c}$, where $\tau$ is the shear stress, $\tau_{0}$ is the cohesion and $\sigma_{n}$ is the normal stress (Fig. 12a). Using the previously applied equation, we obtain the coefficient of

Table 8 Comparison between friction coefficient at yield stress $\mu_{y}$ and coefficient of internal friction $\mu$ at peak stress with extrapolated unconfined compressive strength $\left(\sigma_{U C S}\right) . \mu$ and $\sigma_{U C S}$ were determined using a linear Mohr-Coulomb failure criterion

\begin{tabular}{llll}
\hline $\begin{array}{l}\text { Sample orienta- } \\
\text { tion }\end{array}$ & $\mu_{y}[-]$ & $\mu[-]$ & $\sigma_{U C S}[\mathrm{MPa}]$ \\
\hline$p$ & $0.26 \pm 0.14$ & $0.44 \pm 0.1$ & $102 \pm 34$ \\
$z$ & $0.16 \pm 0.11$ & $0.31 \pm 0.13$ & $106 \pm 36$ \\
$s$ & $0.17 \pm 0.04$ & $0.31 \pm 0.06$ & $121 \pm 16$ \\
\hline
\end{tabular}

$p\left(0^{\circ}\right), z\left(45^{\circ}\right)$ and $s\left(90^{\circ}\right)$ represent the sample orientation between the loading direction relative to the bedding plane

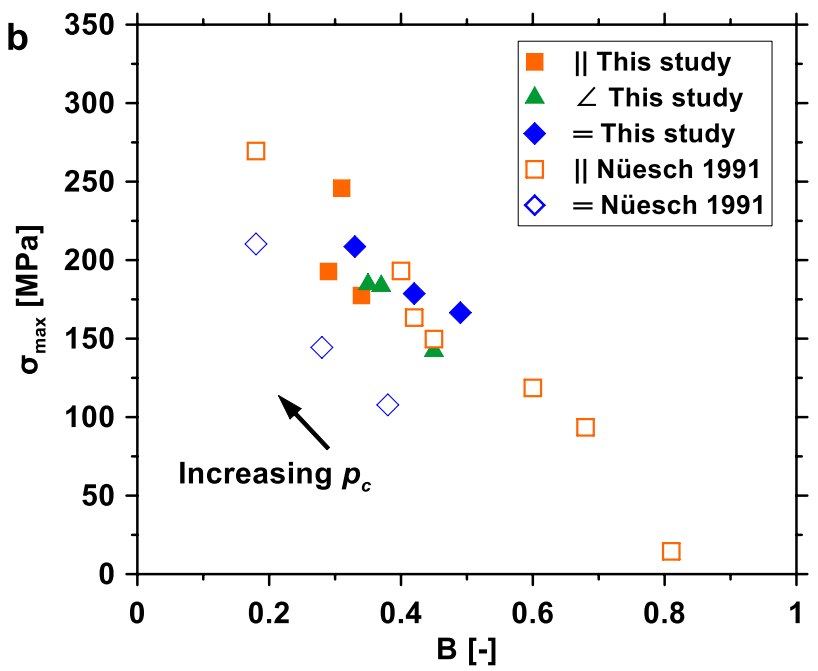

(Nüesch 1991) represented by open symbols. Shown friction coefficients were estimated from axial peak stress $(\mu)$ and yield stress at onset of non-linearity $\left(\mu_{y}\right)$ of the sandy facies. (b) Correleation between the peak strength $\sigma_{\max }$ and brittleness $B$ (b) of both facies determined at different confining pressures $p_{c}$ (c.f., a) 
internal friction $\mu$ at bulk failure that differs from $\mu_{y}$, which is determined from the axial stress at damage initiation. Least square regression yields $\mu_{p} \approx 0.44 \pm 0.10, \mu_{z} \approx 0.31 \pm 0.13$, $\mu_{s} \approx 0.31 \pm 0.06$ (Table 8) and friction angles $\left(\phi=\tan ^{-1} \mu\right)$ of $\phi_{p}=24^{\circ}, \phi_{z}=17^{\circ}$ and $\phi_{s}=17^{\circ}$ for p-, z- and s-samples, respectively (Fig. 12a). The resulting angles between shear zone and samples axis $\left(\theta=45^{\circ}-\phi / 2\right.$, Jaeger et al. 2007) are between $33^{\circ}$ and $36^{\circ}$, and in good agreement with measured angles of $30-47^{\circ}$ of sheared samples (Table 4).

Compared to the shaly facies of Opalinus Clay, samples from the sandy facies in p-and s-orientation are significantly stronger (Fig. 4d, Fig. 12a), as they contain more quartz and other clastic minerals (e.g., Pearson et al. 2003). Nüesch (1991) performed undrained triaxial deformation experiments on the shaly facies of Opalinus clay at $T=20^{\circ} \mathrm{C}, \dot{\varepsilon}=$ $1.3 \times 10^{-7}-8.4 \times 10^{-5} \mathrm{~s}^{-1}$ and $p_{c}<400 \mathrm{MPa}$, using air-dried samples with $1.8 \mathrm{wt} \%$ water content. He estimated internal friction coefficients of $\mu_{p} \approx 0.28$ (parallel) and $\mu_{s} \approx 0.26$ (perpendicular) to bedding that are lower than our estimates for the sandy facies. Our observation that samples taken from the sandy facies are stronger with higher elastic moduli (Figs. 4, 12) is consistent with previous studies (cf., Popp and Salzer 2007; Gräsle and Plischke 2010, 2011; Amann et al. 2011, 2012; Vöbel et al. 2014; Siegesmund et al. 2014; Wild and Amann 2018; Favero et al. 2018; Giger et al. 2018; Zhang and Laurich 2019; Minardi et al. 2020).

As for other clay-rich rocks, previous and our observations indicate that strengths and elastic properties of Opalinus Clay samples depend significantly on mineralogical composition, in particular on the respective content of clay minerals, quartz, feldspar and carbonates (e.g., Lupini et al. 1981; Chiarelli et al. 2000; Ikari et al. 2007, 2009; Crawford et al. 2008; Kaufhold et al. 2013; Kohli and Zoback 2013; Rybacki et al. 2015; Fang et al. 2017; Herrmann et al. 2018). In addition, the fraction of coarse-grained mineral clasts (Nüesch 1991; Ferrari et al. 2020) and varying burial depth and geological uplift (Ferrari et al. 2016; Favero et al. 2016; Crisci et al. 2019) were found to be important factors affecting strength. Compared to other clay-rich shales, coefficients of internal friction for Opalinus Clay are in the same range compared to published data on Posidonia shale $\left(\mu_{s} \approx 0.16-0.39\right)$ and Upper Bowland Shale $\left(\mu_{s} \approx 0.39\right)$ deformed at $p_{\mathrm{c}}<100 \mathrm{MPa}$ (Rybacki et al. 2015; Herrmann et al. 2018), Wilcox Shale $\left(\mu_{p} \approx 0.48, \mu_{z} \approx 0.3\right.$ and $\mu_{s} \approx 0.38$ ) at $p_{\mathrm{c}}<200 \mathrm{MPa}$ (Ibanez and Kronenberg 1993), Tournemire Shale $\left(\mu_{p} \approx 0.23, \mu_{z} \approx 0.23\right.$ and $\left.\mu_{s} \approx 0.27\right)$ at $p_{\mathrm{c}}<80 \mathrm{MPa}$ (Bonnelye et al. 2017a) and Eagle Ford and Haynesville Shale $\left(\mu_{p, s} \approx 0.3-0.5\right)$ deformed parallel and perpendicular to the bedding orientation at $p_{\mathrm{c}}<70 \mathrm{MPa}$ (Sone and Zoback 2013).

Interestingly, friction values at yield $\left(\mu_{y}\right)$ are lower than bulk coefficients of internal friction $\mu$ (Table 8). The difference may be associated with different acting mechanisms (e.g., microcracking or particle sliding) related to the fabric of the sample (e.g., sample orientation, distribution of quartz- and clay-rich layers). Comparing our results to the friction coefficients of several phyllosilicates and simulated gouges made of quartz-clay mixtures (Saffer and Marone 2003; Tembe et al. 2010; Behnsen et al. 2012), we find $\mu_{y}$ values close to the friction coefficients of pure clay minerals or the clay-rich end-member of gouge mixtures $(\mu \approx$ $0.1-0.3)$. On the other hand, the determined bulk friction $\mu$ corresponds better to friction coefficients of gouge mixtures with increased quartz content between 40 and $60 \mathrm{wt} \%$ ( $\mu \approx 0.3-0.6)$ (Tembe et al. 2010). Furthermore, friction values at yield $\mu_{y}$ of the sandy facies samples are close to bulk coefficients of internal friction for shaly facies OPA $(\mu=0.26-0.28)$ determined by Nüesch (1991). For the deformation behavior of the sandy facies samples, this may suggest different prevailing deformation mechanisms acting at $\sigma_{y}$ and $\sigma_{\max }$. Damage initiation might be more influenced by clay minerals and granular flow, whereas bulk failure is more affected by microfracturing of clastic minerals (e.g., quartz, calcite).

Extrapolated unconfined compressive strengths $\left(\sigma_{\mathrm{UCS}}\right)$ of tested p- and s-samples (Table 8) are more than twice as high as reported previously (e.g., Jaeggi et al. 2014). This may be explained by the transition from dilatancy to increased sample compaction at elevated pressures, suggesting a non-linear relationship between shear strength and confining pressures as reported for shaly Opalinus Clay (e.g., Naumann et al. 2007; Amann et al. 2012; Wild and Amann 2018), Tournemire Shale (Niandou et al. 1997; Masri et al. 2014), Meuse-Haute/Marne Claystone (Hu et al. 2014) and Wilcox Shale (Ibanez and Kronenberg 1993).

Based on the definition of the used brittleness index, $B$ values of the sandy as well as the shaly facies OPA (determined from the data obtained by Nüesch 1991) vary substantially with applied $p_{c}$. Therefore, $B$ reveals a negative correlation with peak strength (Fig. 12b) illustrating the increased hardening behavior with increasing confining pressure (Fig. 4f). However, irrespective of the clay content, Young's moduli of Opalinus Clay show no clear correlation with increasing confining stress (Fig. 4e), peak strength or brittleness (Table4).

\subsection{Effect of Temperature and Strain Rate on Deformation Behavior}

\subsubsection{Temperature}

Temperature variations up to $T=200{ }^{\circ} \mathrm{C}$ show little effect on the mechanical behavior of dry Opalinus Clay samples (Fig. 6). The peak strength of p-samples remains unaffected by temperature changes, whereas $\mathrm{z}$ - and s-samples reveal minor weakening with increasing temperatures up to $150{ }^{\circ} \mathrm{C}$ 
(Fig. 6d). The latter is in agreement with the temperature sensitivity of s-samples obtained from the shaly facies, as observed by Nüesch (1991) at $p_{\mathrm{c}}=100 \mathrm{MPa}$ (Fig. 6d). The weakening may be a consequence of the low residual water content (about $0.4 \mathrm{wt} \%$ ) remaining in the used dried samples. Because of the very low permeability of clay-rich rocks at undrained test conditions, increasing temperatures may lead to elevated pore pressure and, thus, to a reduction of the effective mean stress (e.g., Monfared et al. 2011b; Mohajerani et al. 2012; Menaceur et al. 2016). In addition, thermally driven pressurization may facilitate interparticle motion of clay particles due to water adsorption (e.g., Ibanez and Kronenberg 1993), resulting in a reduction of the inherent cohesion and friction resistance of the material (e.g., Sammis et al. 2011; Zhang 2017). The latter effect is expected to be minor for $\mathrm{p}$-samples with strong layers containing clastic minerals, which may explain the negligible influence of temperature on strength.

Interestingly, strength increases slightly for z- and s-samples at $T=200{ }^{\circ} \mathrm{C}$. This may be caused by mobilization and removal of interlayer clay bound water, which can lead to mechanical strengthening by the reduction of interlayer spacing between individual clay particles and the collapse of nanopores. Therefore, frictional resistance between clay particles, and stiffness and strength may all increase (Moore and Lockner 2004; Reches and Lockner 2010; Sammis et al. 2011; Kubo and Katayama 2015; Zhang et al. 2017; Rassouli and Zoback 2018; Sharma et al. 2019). From X-ray diffraction-, infrared spectroscopy and thermogravimetric analyses, strengthening caused by inter- and intracrystalline clay mineral dehydration may be expected at temperatures $T>150{ }^{\circ} \mathrm{C}$ (e.g., Mikhail and Guindy 1971; Bala et al. 2000; Schleicher et al. 2015; Schnetzer et al. 2016). However, $\mathrm{X}$-ray diffraction patterns of samples tested at varying temperatures remain similar.

Temperature sensitivity of strength and elastic properties of samples were further related to an increased contribution of viscoplastic processes (e.g., dislocation glide in phyllosilicates) and/or thermally enhanced subcritical crack growth (stress corrosion) during deformation (e.g., Kranz et al. 1982; Atkinson 1984; Kronenberg et al. 1990; Ibanez and Kronenberg 1993; Mares and Kronenberg 1993; Heap et al. 2009; Rybacki et al. 2015; Herrmann et al. 2018). However, since enhanced dislocation activity of clastic and clay minerals was not resolved at TEM scale, we cannot verify this by our microstructural analysis.

\subsubsection{Strain Rate}

The influence of strain rate on the peak strength, Young's modulus and brittleness of tested samples is weak and depends on orientation between loading direction and bedding (Fig. 7). Taking sample-to-sample reproducibility into account, peak strengths and Young's modulus of p-samples decrease slightly with decreasing strain rates (Table 6, Fig. 7d, e). This is in line with measurements on the shaly facies samples of Opalinus Clay from Nüesch (1991), also showing a weak reduction of peak strengths for $\mathrm{p}$-samples (Fig. 7d). In contrast, for s-samples, strength and Young's modulus of sandy facies OPA appear to increase with decreasing strain rate, whereas strength of the shaly facies seems to be unaffected.

Macro- and microfabric analysis of deformed sandy facies samples show that semi-brittle deformation involves a combination of brittle (e.g., microfracturing, particle sliding) and crystal plastic (e.g., dislocation glide of phyllosilicates) deformation mechanisms. At low strain rates, strength of samples is expected to decrease due to the activation of ratedependent plastic deformation mechanisms (e.g., Ibanez and Kronenberg 1993). This may indicate that potentially ratedependent micro-mechanisms (e.g., dislocation glide and reorientation of minerals) are more important at low rates, but cracking and cataclastic flow is important at high rates (Chong et al. 1980; Chong and Boresi 1990; Bonnelye et al. 2017b). The decrease of strengths and Young's moduli with decreasing strain rate was also found for several other clayrich rocks. Assuming dislocation glide within clay minerals, the relation between strain rate and strength was expressed by $\dot{\varepsilon} \propto \exp \left(\alpha \times \sigma_{\max }\right)$ (Chong et al. 1980; Chong and Boresi 1990; Ibanez and Kronenberg 1993; Kwon and Kronenberg 1994; Rybacki et al. 2015; Herrmann et al. 2018; Hou et al. 2019). For the empirical constant $\alpha$, we obtain $\alpha_{p}=0.53$ for the sandy facies and $\alpha_{p}=0.6$ for the shaly facies measured by Nüesch (1991). These values are comparable to the results obtained by Ibanez and Kronenberg (1993) for Wilcox Shale ( $\alpha_{p}=0.3, \alpha_{v}=0.5$ and $\alpha_{s}=0.36$ ), Rybacki et al. (2015) for Posidonia (Dotternhausen and Wickensen location) Shale ( $\alpha_{s}=0.48$ and 0.27 ) as well as for Posidonia (Harderode location) and Bowland Shale ( $\alpha_{s}=0.16$ and 0.57) (Herrmann et al. 2018). At high strain rates, energy dissipation by plastic processes is limited, but an increasing number of micro-cracks are expected to be activated (Chong and Boresi 1990; Hou et al. 2019). Cracking and dilatancy are expected to contribute to work hardening until sample failure occurs. In addition, the increase of strength at high strain rates might be explained by a strain rate-dependent fracture toughness as suggested for the deformation of shales (Bonnelye et al. 2017a, b; Mahanta et al. 2017).

Interestingly, z- and s-samples responded differently to the variation of applied strain rate compared to p-samples (Fig. 7). Possibly, this may be related to compositional heterogeneity and sample-to-sample variation. For z- and s-samples we observed that localization and sample fracture patterns depend on the thickness of clay-rich layers. With increasing initial thickness, stress-strain curves and macrofabric of deformed samples reveal less localized 
behavior and increased strain partitioning in clay-rich layers. Furthermore, time-dependent reorientation of clay particles and shear-induced compaction of clay-rich layers may also be responsible for the apparent rate-dependent strength observed for s-samples. However, strain rate dependency of the investigated samples is low and presumably overprinted by sample inhomogeneity.

\subsection{The Effect of Water}

Water saturation of samples shows a strong effect on the deformation behavior of sandy Opalinus Clay specimens. Peak strengths of saturated samples are reduced for all tested sample orientations (Figs. 8,13). We found an inverse linear relationship between water content (wt\%) and peak strength. The resulting weakening gradients due to increasing water content were $-9 \mathrm{MPa} / \mathrm{wt} \%,-15 \mathrm{MPa} / \mathrm{wt} \%$ and $-14 \mathrm{MPa} /$ wt $\% \mathrm{H}_{2} \mathrm{O}$ for $\mathrm{p}-$, $\mathrm{z}-$ and s-samples, respectively. For comparison, the reduction is about $-19 \mathrm{MPa} / \mathrm{wt} \%$ for s-samples of the shaly facies tested at $T=20^{\circ} \mathrm{C}$ and $p_{\mathrm{c}}=75 \mathrm{MPa}$ (Nüesch 1991), which is in good agreement with our results (Fig. 13a). With increasing saturation, Young's modulus of p-samples decreased by about $-1 \mathrm{GPa} / \mathrm{wt} \% \mathrm{H}_{2} \mathrm{O}$ and by $-0.3 \mathrm{GPa} / \mathrm{wt} \% \mathrm{H}_{2} \mathrm{O}$ for s-samples, whereas there was no significant effect of water saturation on the Young's modulus of z-samples (Fig. 13b). A comparable weakening effect of increasing water saturation on peak strength was also found for Callovo-Oxfordian Clay - $6 \mathrm{MPa} / \mathrm{wt} \%$ (Chiarelli et al. 2000), Tournemire Shale - $10 \mathrm{MPa} / \mathrm{wt} \%$ (Valès et al. 2004), Wilcox Shale - $45 \mathrm{MPa} / \mathrm{wt} \%$ (Ibanez and Kronenberg 1993) and Alum Shale - $16 \mathrm{MPa} / \mathrm{wt} \%$ (Rybacki et al. 2015).

The decrease in strength and stiffness properties with increasing water content is commonly attributed to the increased thickness of adsorbed interlayer and interparticle bonded water of clay minerals (e.g., Nüesch 1991; Ibanez and Kronenberg 1993). As a result, the frictional movement of individual clay particles is facilitated due to decreasing solid-solid contacts (e.g., Sammis et al. 2011; Zhang 2017; Zhang and Laurich 2019). Furthermore, excess pore pressures may develop in saturated samples due to undrained boundary conditions at elevated pressures and temperatures as well as during differential loading, reducing the effective mean stress and frictional strength (Ibanez and Kronenberg 1993; Islam and Skalle 2013). In contrast, decreasing saturation can lead to an increase of capillary and osmotic suction inside the pores of clay aggregates, which increases the shear resistance between individual grains resulting in increased strength and elastic properties (e.g., Zhang et al. 2012; Wild et al. 2015; Minardi et al. 2016; Zhang 2017).

We observed stronger weakening for $\mathrm{z}$ - and s-samples due to increased water saturation compared to p-samples (Figs. 8, 13a). This may be explained by orientation-dependent excess pore pressure, possibly related to anisotropic
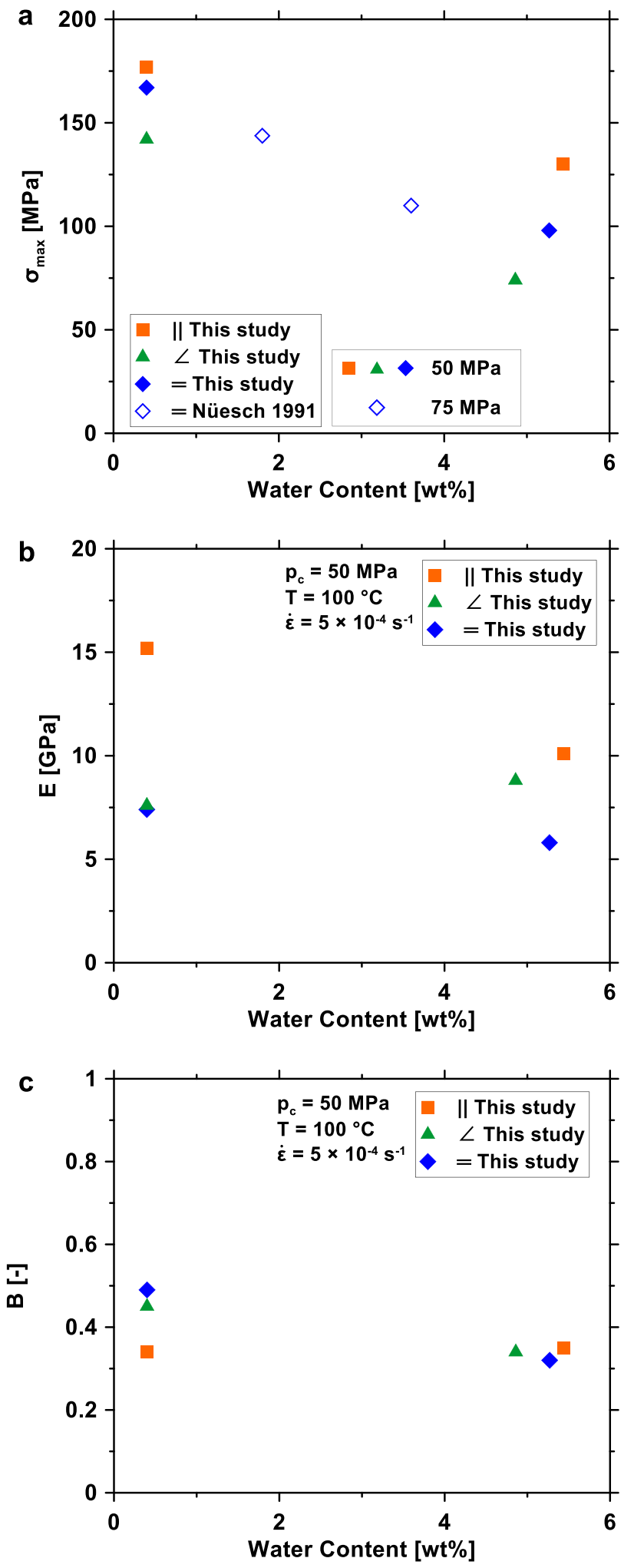

Fig. 13 Influence of water content on the peak strength $\sigma_{\max }$ of the sandy facies (this study), tested at $p_{c}=50 \mathrm{MPa}, T=100{ }^{\circ} \mathrm{C}$ and $\dot{\varepsilon}=5 \times 10^{-4} \mathrm{~s}^{-1}$ in comparison to the results of the shaly facies, tested at $p_{c}=75 \mathrm{MPa}$, $T=20^{\circ} \mathrm{C}$ and $\dot{\varepsilon}=3.0 \times 10^{-4} \mathrm{~s}^{-1}$ (Nüesch 1991), represented by open symbols (a). Correleation between water content as well as Young's modulus $E(\mathbf{b})$ and brittleness $B(\mathbf{c})$ of the sandy facies. Deformation conditions are indicated 
permeability, and by the transversely isotropic elastic behavior of Opalinus Clay. The generation of excess pore pressure depends on the permeability of the deformed rock (AlBazali et al. 2008). Since the permeability of OPA is lower perpendicular to bedding than parallel to it (e.g., NAGRA 2002; Keller et al. 2013a; Keller and Holzer 2018), pore pressure in parallel oriented samples may equilibrate faster during deformation than for the other two sample orientations. Furthermore, p- samples are stiffer and therefore generate less pore pressure from compaction compared to the more compliant z- and s-samples (e.g., Islam and Skalle 2013; Wild et al. 2015; Wild and Amann 2018). In addition, microstructures of deformed samples reveal substantial microcracking in p-samples as opposed to z- and s-samples. It is conceivable that dilatant microcracking increases the pore volume and reduces the pore pressure during deformation (e.g., Brace and Martin 1968; Islam and Skalle 2013; Wild and Amann 2018). The generation and dissipation of pore pressure in undrained experiments is therefore strongly controlled by dilatancy (Swan et al. 1989; Hou et al. 2014). In consequence, the generated pore pressure in parallel samples would be lower and, therefore, the effective mean stress higher, which would result in higher strength.

Testing p-samples with porous spacers revealed that at drained conditions strength of the saturated sample was reduced by about $36 \%$ compared to undrained conditions, while dry samples were unaffected (Fig. 3a, Table 3). Expecting reduced mean effective stress at undrained conditions, the low strength of the saturated sample tested at drained conditions is counterintuitive. Pore pressure generation in low permeable samples highly depends on the applied strain rate and drainage condition, maybe explaining the strong effect for saturated samples (e.g., Swan et al. 1989; Al-Bazali et al. 2008; Monfared et al. 2011a; Belmokhtar et al. 2018; Minardi et al. 2020). To check if samples are drained at the applied strain rate, we estimated the time required during a drained shear experiment to dissipate $95 \%$ of the generated excess pore pressure until failure $\left(t_{f}\right)$ using $t_{f}=1.667 \times L^{2} / c$ (Head and Epps 2014). Using $t_{f}$, a sample length of $L=20 \mathrm{~mm}$ and estimated axial strain to failure between 2 and 5\%, the predicted strain rate is between $6 \times 10^{-8}$ and $1.2 \times 10^{-7} \mathrm{~s}^{-1}$, which is more than one magnitude lower than the lowest strain rate applied in this study. Hence, in our experiments, most likely heterogeneous excess pore pressure was generated during deformation, which may explain the low strength obtained for the saturated sample tested with a porous spacer.

\subsection{Influence of Rock Fabric and Composition}

In addition to experimental boundary conditions, heterogeneity of the macro- and microfabric of the specimens strongly affect the deformation behavior of Opalinus Clay of the sandy facies. Strength increases with increasing amount of interconnected quartz-rich layers and/or seems to increase with decreasing porosity (e.g., OT04B, OT16, OT22), whereas samples with more clay-rich layers display lower strength. Several studies show that sandy facies Opalinus Clay samples with higher quartz and carbonate (carbonate cement) content display higher stiffness and strength properties (e.g., Gräsle and Plischke 2010; Kaufhold et al. 2013), and are less sensitive to volumetric expansion due to increasing water content (Minardi et al. 2016). For shaly facies OPA, Crisci et al. (2019) found a positive correlation between clay mineral content and porosity, which both contribute to increasing compressibility. Becker (2012) observed a positive correlation between porosity and clay mineral content as well as a negative correlation between porosity and calcite content (Peters et al. 2011; Houben et al. 2014; Philipp et al. 2017). Furthermore, a combination of microcracking and plasticity was observed in laboratory deformation experiments on Callovo-Oxfordian Clay. It was shown that the material deformed more brittle with increasing calcite content and more ductile with increasing clay and/or water content (Chiarelli et al. 2000; Desbois et al. 2017). In an effort to describe the relationship between the influence of composition and rock fabric, Abou-Chakra Guéry et al. (2008) linked observed microstructural deformation mechanisms of individual compositional constituents to reproduce laboratory experiments of Callovo-Oxfordian Clay by applying a micromechanical elastoplastic damage model with a simplified three-phase medium composed of calcite and quartz distributed in a clay matrix.

In a simplified way, the combined influence of composition and bedding orientation on the mechanical behavior may be described by effective medium theories (e.g., Mavko et al. 2009). As commonly assumed for shales (e.g., Sone and Zoback 2013; Rybacki et al. 2015; Herrmann et al. 2018), we separate the composition of OPA into weak (clay minerals, total organic carbon and porosity) and strong (quartz, feldspar, carbonates, feldspar and pyrite) components and respective compositional end-members. For elastic properties, we used the strong $\left(E_{\text {strong }}=91 \mathrm{GPa}\right)$ and weak $\left(E_{\text {weak }}\right.$ $=3 \mathrm{GPa}$ ) end-member Young's moduli determined by Herrmann et al. (2018). For the lower limit of the compressive strength, we used the strength of Boom Clay that is extrapolated to $p_{c}=50 \mathrm{MPa}$, resulting in $\sigma_{\text {max-weak }}=35.5 \mathrm{MPa}$ (Bouazza et al. 1996) and the peak strength of Novaculite $\sigma_{\text {max-strong }}=699 \mathrm{MPa}$ (Rybacki et al. 2015) for the respective strong end-member. Using the calculated strength and elastic end-member values, we plotted the Voigt (isostrain), Reuss (iso-stress) and Voigt-Reuss-Hill (mean value of Voigt and Reuss bound) average against the volumetric content of weak components (Fig. 14a, b). For the sandy facies of OPA, we used the average composition of our mineralogical analysis (Table 1) and the average peak 


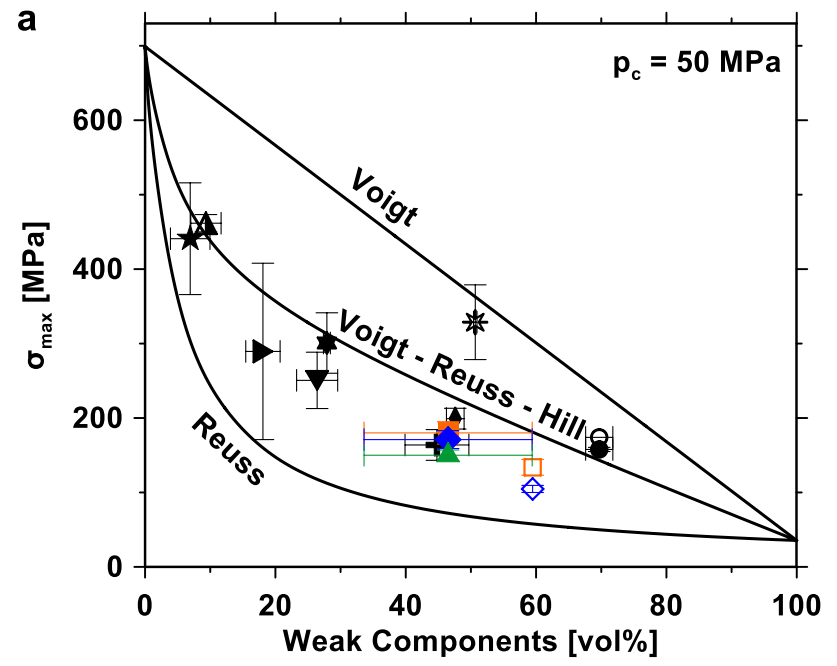

\begin{tabular}{|llllll|}
\hline IIOPA sandy & $\star$ & $=$ BOW & $\Delta$ & $\|,=$ BAR 2 \\
= OPA sandy & + & $=$ POS & & $\|,=$ HAY 1 \\
L OPA sandy & 0 & II ALM & $\star$ & $\|,=$ HAY 2 \\
$\square$ & I OPA shaly & 0 & $=$ ALM & $\nabla$ & $\|,=$ EGF 1 \\
$\diamond$ & $=$ OPA shaly & $\star$ & $\|,=$ BAR 1 & $\|,=$ EGF 2
\end{tabular}

Fig. 14 Peak strength $\sigma_{\max }(\mathbf{a})$ and Young's modulus $E$ (b) of the sandy facies, obtained at $p_{c}=50 \mathrm{MPa}$, strain rates of $\dot{\varepsilon}=1 \times 10^{-3}$ $5 \times 10^{-6} \mathrm{~s}^{-1}$ and temperatures of $T=25-200{ }^{\circ} \mathrm{C}$, as well as of the shaly facies measured by Nüesch (1991), tested at $p_{c}=50 \mathrm{MPa}$, $T=20{ }^{\circ} \mathrm{C}$ and $\dot{\varepsilon}=8.4 \times 10^{-5}-8.8 \times 10^{-5} \mathrm{~s}^{-1}$, as a function of the volumetric fraction of weak components (clay minerals, total organic carbon and porosity). Experimental data are compared to mechanical

strength and Young's modulus determined at different strain rates and temperatures, which only show a minor effect on deformation behavior. For comparison, we included data of the shaly facies determined by Nüesch (1991) at similar confining pressure and strain rate conditions but at temperatures of $T=20^{\circ} \mathrm{C}$. Furthermore, experimental data of Upper Bowland (BOW), Alum (ALM) and Posidona (POS) Shale, measured by Rybacki et al. (2015) and Herrmann et al. (2018) at $p_{\mathrm{c}}=50 \mathrm{MPa}, \dot{\varepsilon}=5 \times 10^{-6} \mathrm{~s}^{-1}$ and $T=100^{\circ} \mathrm{C}$ were included for comparison. To further extend the range of material composition, mechanical data from the American, organic-rich gas shales Barnett (BAR), Haynesville (HAY) and Eagle Ford (EGF) obtained by Sone and Zoback (2013) were included. Strength and Young's modulus of these rocks were measured at $p_{\mathrm{c}} \approx 10-60 \mathrm{MPa}, \dot{\varepsilon}=10^{-5} \mathrm{~s}^{-1}$ at room temperature after conducting several creep steps at different confining and differential pressures. We used the coefficients of internal friction determined by Sone and Zoback (2013) $\left(\mu_{p, s}\right.$ $\approx 0.3-0.8$ ) to extrapolate strength values to pressure conditions of $p_{\mathrm{c}}=50 \mathrm{MPa}$. Due to the low strength anisotropy of the tested shales, $\mathrm{p}$ - and s-samples were treated equally by Sone and Zoback (2013), resulting in one extrapolated strength value for both orientations. Used values of Young's

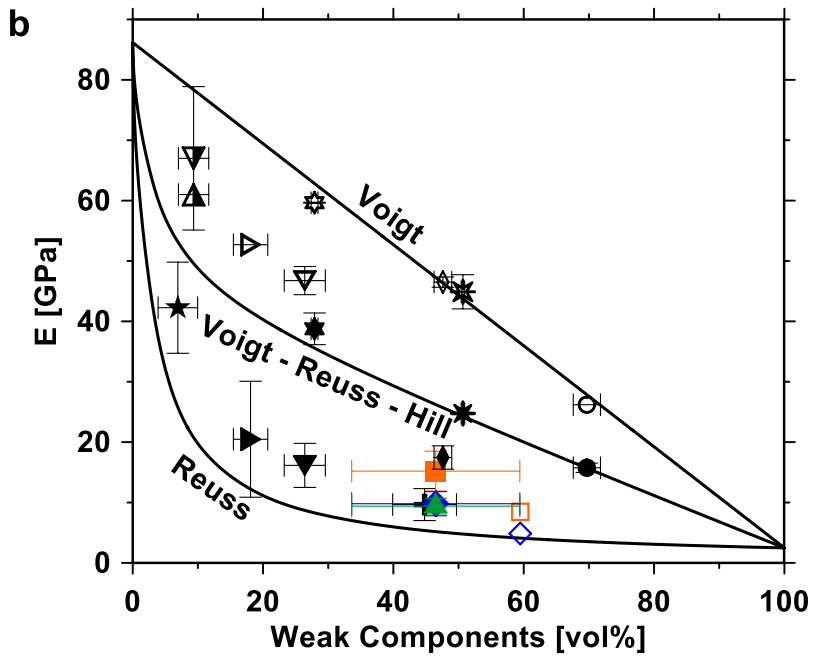

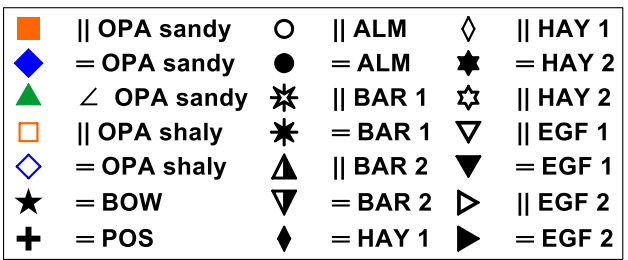

results of black shales (BOW, POS, ALM) measured by Rybacki et al. (2015) and Herrmann et al. (2018) deformed at $p_{c}=50 \mathrm{MPa}, \dot{\varepsilon}=$ $5 \times 10^{-4} \mathrm{~s}^{-1}$ and $T=100{ }^{\circ} \mathrm{C}$. Furthermore, mechanical data of American gas shales from Sone and Zoback (2013) are shown (BAR, HAY, EGF). Note here that the compressive strength for the latter shales was extrapolated to $p_{c}=50 \mathrm{MPa}$ and the influence of confining pressure on Young's Modulus was neglected

moduli represent an average over the range of the applied experimental conditions.

Young's moduli and peak strengths of OPA from both facies plot between the Voigt-Reuss-Hill and Reuss bounds (Fig. 14). Elastic properties of z- and s-samples plot closer to the lower Reuss bound, suggesting stresses are similar between individual composite phases. This is in agreement with the common assumption that elastic deformation of $\mathrm{z}$ - and s-samples is governed by strain accumulation in compliant layers of weak phases. In contrast, p-samples show iso-strain of weak and rigid layers. The elastic anisotropy of OPA is low compared to the calculated bounds. The mechanical properties of the sandy facies samples show a small influence of compositional variations relative to the bounds. This is consistent with the previous results showing increasing strength and Young's moduli with increasing content of strong phases once exceeding a threshold of about 70vol\% (Crawford et al. 2008; Kohli and Zoback 2013; Bourgh 2015; Hermann et al. 2018). The increase may be explained by a compositional rock fabric transition in which deformation of interconnected weak phases changes to a structure in which deformation is supported by a loadbearing framework of strong phase minerals such as quartz 
or feldspar. However, determined composition of the tested sandy facies samples is still above the proposed threshold of $30 \mathrm{vol} \%$ of weak phases.

Compared to samples from the shaly facies, the observed anisotropies of strength and elastic moduli are lower for samples of the sandy facies tested in our study. This might be associated with the higher quartz content of the sandy facies inhibiting the alignment of phyllosilicates during diagenesis (e.g., Wenk et al. 2008; Klinkenberg et al. 2009; Kaufhold et al. 2013; Siegesmund et al. 2014). Interestingly, compressive strength of $\mathrm{p}$ - and s-samples of OPA and deeply buried $(>1.5 \mathrm{~km})$ shales plot close to the Voigt-Reuss-Hill bound (Fig. 14a). On the other hand, these shales display a higher elastic anisotropy in comparison to Opalinus Clay with Young's moduli of $\mathrm{p}$-samples closer to the upper Voigt (iso-strain) bound (Fig. 14b). For p- and s-samples, this suggests that apart from the amount of weak components, the rock fabric as well as the degree of diagenesis, cementation and consolidation have a stronger influence on the elastic anisotropy, failure mode and deformation behavior of shales in comparison to compressive strength anisotropy (e.g., Gutierrez et al. 1996; Bjørlykke and Høek 1997; Corkum and Martin 2007; Nygård et al. 2004; Loucks et al. 2012; Sone and Zoback 2013; Desbois et al. 2018; Crisci et al. 2019).

\section{Conclusions}

Triaxial deformation experiments were performed on the sandy facies of Opalinus Clay to investigate its anisotropic mechanical behavior as a function of the applied confining pressure, temperature, strain rate and water content as well as the response to varying drainage condition and pre-consolidation. Within the range of tested conditions, the sandy facies displays brittle to semi-brittle deformation behavior. The compressive strength as well as the Young's modulus and brittleness depend on the loading direction with respect to the bedding orientation. The highest strength values and Young's moduli are measured for parallel oriented samples.

The applied confining pressure as well as the degree of water saturation was found to have the most important effect on the deformation behavior. Both, the peak strength and Young's modulus decrease with increasing degree of saturation, whereas only the peak strength increases with increasing confining pressure. On the other hand, effects of preconsolidation, drainage condition, temperature and strain rate are minor for samples with a reduced water content of about $0.4 \mathrm{wt} \%$. Apart from the influence of the applied deformation conditions on the mechanical behavior, the strong heterogeneity of the sandy facies characterized by alternating bedding of clay-rich and quartz-rich sandy layers also influences deformation. Samples with an increased amount of sand layers display higher peak strength and Young's modulus.

The deformation behavior of samples that are deformed parallel to the bedding plane is characterized by a distinct pre-failure strain hardening with an increased contribution of micro cracking. Samples deformed at an angle of $45^{\circ}$ and $90^{\circ}$ to the bedding plane display minor hardening. Microstructures of deformed samples reveal evidence that the sandy facies fails by dominantly brittle mechanisms involving cataclastic and granular flow (microfractruring, frictional particle sliding) at the tested conditions. However, with increasing shear strain, grain size reduction and matrix intrusion in fractured grains are leading to shear compaction and resealing of the damaged zone. Friction coefficients determined at yield stress are lower compared to internal coefficients of friction obtained at peak strength.

In comparison to the shaly facies, the sandy facies of Opalinus Clay displays higher strength and Young's modulus but lower anisotropy likely caused by the increased amount of strong phase minerals (e.g., quartz, carbonates). This observation is also in agreement with applied effective medium theories. For $45^{\circ}$ and $90^{\circ}$ oriented samples, determined peak strength and Young's modulus of both facies plot close to the iso-strain Reuss bound. Despite the lower amount of weak mineral phases, this suggests that the deformation behavior of the sandy facies is mainly influenced by the compliant phyllosilicate-rich matrix in both sample orientations.

Acknowledgements The authors acknowledge the financial support for the iCross project by the Federal Ministry of Education and Research (Project Number 02NUK053D), the Helmholtz Association (Project Number SO-093) and the GFZ German Research Centre for Geosciences Potsdam. Furthermore, Michael Naumann is highly appreciated for the support of triaxial deformation experiments. We thank Stefan Gehrmann for sample preparation as well as Vladimir Roddatis, Anja Schreiber and Ilona Schäpan for assistance at the SEM. Furthermore, we thank two anonymous reviewers, who helped to improve the manuscript with their constructive comments.

Funding Open Access funding enabled and organized by Projekt DEAL.

Availability of data and material Data availability on request.

\section{Declarations}

Conflict of interest The authors declare that they have no conflict of interest.

Open Access This article is licensed under a Creative Commons Attribution 4.0 International License, which permits use, sharing, adaptation, distribution and reproduction in any medium or format, as long as you give appropriate credit to the original author(s) and the source, provide a link to the Creative Commons licence, and indicate if changes were made. The images or other third party material in this article are included in the article's Creative Commons licence, unless indicated otherwise in a credit line to the material. If material is not included in 
the article's Creative Commons licence and your intended use is not permitted by statutory regulation or exceeds the permitted use, you will need to obtain permission directly from the copyright holder. To view a copy of this licence, visit http://creativecommons.org/licenses/by/4.0/.

\section{References}

Abou-Chakra Guéry A, Cormery F, Shao JF, Kondo D (2008) A micromechanical model of elastoplastic and damage behavior of a cohesive geomaterial. Int J Solids Struct 45:1406-1429. https:// doi.org/10.1016/j.ijsolstr.2007.09.025

Al-Bazali T, Zhang J, Chenevert ME, Sharma MM (2008) Experimental and numerical study on the impact of strain rate on failure characteristics of shales. J Petrol Sci Eng 60:194-204. https:// doi.org/10.1016/j.petrol.2007.09.001

Amann F, Button EA, Evans KF, Gischig VS, Blumel M (2011) Experimental study of the brittle behavior of clay shale in rapid unconfined compression. Rock Mech Rock Eng 44:415-430. https:// doi.org/10.1007/s00603-011-0156-3

Amann F, Kaiser P, Button EA (2012) Experimental study of brittle behavior of clay shale in rapid triaxial compression. Rock Mech Rock Eng 45:21-33. https://doi.org/10.1007/s00603-011-0195-9

Amann F, Vogelhuber M, von Moos A (2015) Assessment of geomechanical properties of intact opalinus clay. Unpublished expert report ENSI 33:461

Atkinson BK (1984) Subcritical crack growth in geological materials. J Geophys Res Solid Earth 89:4077-4114. https://doi.org/10.1029/ JB089iB06p04077

Bala P, Samantaray BK, Srivastava SK (2000) Dehydration transformation in Ca-montmorillonite. Bull Mater Sci 23:61-67. https://doi. org/10.1007/BF02708614

Becker JK (2012) HA experiment: laboratory analyses-mineralogy and petrophysical properties on core material from the BVA boreholes. Mont Terri Tech Note TN 2012-38:17

Behnsen J, Faulkner DR (2012) The effect of mineralogy and effective normal stress on frictional strength of sheet silicates. J Struct Geol 42:49-61. https://doi.org/10.1016/j.jsg.2012.06.015

Belmokhtar M, Delage P, Ghabezloo S, Conil N (2018) Drained triaxial tests in low-permeability shales: application to the callovo-oxfordian claystone. Rock Mech Rock Eng 51:1979-1993. https://doi.org/10.1007/s00603-018-1442-0

Bishop AW, Henkels DJ (1962) The measurement of soil properties in the triaxial test., 2 edn. Edward Arnold, London

Bjørlykke K, Høeg K (1997) Effects of burial diagenesis on stresses, compaction and fluid flow in sedimentary basins. Mar Petrol Geol 14:267-276. https://doi.org/10.1016/S0264-8172(96) 00051-7

Blackwell D, Frone Z, Richards M (2013) The future of geothermal energy: the shale gas analogy significant electrical EGS resource areas in the US. Trans Geotherm Resour Council 37:117-122

Bock H, Blümling P, Konietzky H (2006) Study of the micro-mechanical behaviour of the Opalinus Clay: an example of co-operation across the ground engineering disciplines. Bull Eng Geol Env 65:195-207. https://doi.org/10.1007/s10064-005-0019-9

Bonnelye A et al (2017a) Strength anisotropy of shales deformed under uppermost crustal conditions. J Geophys Res-Solid Earth 122:110-129. https://doi.org/10.1002/2016jb013040

Bonnelye A et al (2017b) Elastic wave velocity evolution of shales deformed under uppermost crustal conditions. J Geophys Res Solid Earth 122:130-141. https://doi.org/10.1002/2016jb013540

Boosari S, Aybar U, Eshkalak OM (2015) Carbon dioxide storage and sequestration in unconventional shale reservoirs 3
Bossart P, Milnes AG (2017) Mont terri rock laboratory, 20 years of research. Swiss J Geosci 110:1-411. https://doi.org/10.1007/ 978-3-319-70458-6

Bossart P, Thury M (2008) Mont terri rock laboratory-project programme 1996 to 2007 and results, vol 3. Swiss Geological Survey, Wabern

Bouazza A, Van Impe WF, Haegeman W (1996) Some mechanical properties of reconstituted Boom clay. Geotech Geol Eng 14:341-352. https://doi.org/10.1007/BF00421948

Bourg IC (2015) Sealing shales versus brittle shales: a sharp threshold in the material properties and energy technology uses of finegrained sedimentary rocks. Environ Sci Technol Lett 2:255-259. https://doi.org/10.1021/acs.estlett.5b00233

Brace WF, Martin RJ (1968) A test of the law of effective stress for crystalline rocks of low porosity. Int J Rock Mech Min Sci Geomech Abstr 5:415-426. https://doi.org/10.1016/01489062(68)90045-4

Busch A et al (2008) Carbon dioxide storage potential of shales. Int J Greenh Gas Con 2:297-308. https://doi.org/10.1016/j.ijggc. 2008.03.003

Chester FM et al (2013) Structure and composition of the plateboundary slip zone for the 2011 Tohoku-Oki earthquake. Science 342:1208-1211. https://doi.org/10.1126/science.1243719

Chiarelli A-S, Ledesert B, Sibai M, Karami M, Hoteit N (2000) Influence of mineralogy and moisture content on plasticity and induced anisotropic damage of a claystone; application to nuclear waste disposals. Bulletin de la Société Géologique de France 171:621-627. https://doi.org/10.2113/171.6.621

Chong KP, Boresi AP (1990) Strain rate dependent mechanical properties of new albany reference shale. Int J Rock Mech Min Sci Geomech Abstr 27:199-205. https://doi.org/10.1016/01489062(90)94328-Q

Chong KP, Hoyt PM, Smith JW, Paulsen BY (1980) Effects of strain rate on oil shale fracturing. Int J Rock Mech Min Sci Geomech Abstr 17:35-43. https://doi.org/10.1016/0148-9062(80)90004-2

Corkum AG, Martin CD (2007) The mechanical behaviour of weak mudstone (Opalinus Clay) at low stresses. Int J Rock Mech Min 44:196-209. https://doi.org/10.1016/j.ijrmms.2006.06.004

Crawford BR, Faulkner DR, Rutter EH (2008) Strength, porosity, and permeability development during hydrostatic and shear loading of synthetic quartz-clay fault gouge. J Geophys Res Solid Earth. https://doi.org/10.1029/2006jb004634

Crisci E, Ferrari A, Giger SB, Laloui L (2019) Hydro-mechanical behaviour of shallow Opalinus Clay shale. Eng Geol 251:214 227. https://doi.org/10.1016/j.enggeo.2019.01.016

Delage P, Cui YJ, Tang A-M (2010) Clays in radioactive waste disposal. J Rock Mech Geotech 2:111-123. https://doi.org/10.3724/ SP.J.1235.2010.00111

Desbois G, Höhne N, Urai JL, Bésuelle P, Viggiani G (2017) Deformation in cemented mudrock (Callovo-Oxfordian Clay) by microcracking, granular flow and phyllosilicate plasticity: insights from triaxial deformation, broad ion beam polishing and scanning electron microscopy. Solid Earth 8:291-305. https://doi.org/10. 5194/se-8-291-2017

Desbois G, Klaver J, Urai JL, Amann F, Schmatz J (2018) PS Experiment: Microstructural evolution of experimentally deformed, overconsolidated mudrock (shaly Opalinus Clay) based on BIBSEM investigations. Mont Terri Technical Note TN 2017-91:53

Doebelin N, Kleeberg R (2015) Profex: a graphical user interface for the Rietveld refinement program BGMN. J Appl Crystallogr 48:1573-1580. https://doi.org/10.1107/S1600576715014685

Dresen G, Evans B (1993) Brittle and semibrittle deformation of synthetic marbles composed of two phases. J Geophys Res Solid Earth 98:11921-11933. https://doi.org/10.1029/93jb00697

Evans B, Kohlstedt DL (1995) Rheology of Rocks. In: Rock physics \& phase relations: a handbook of physical constants. AGU 
Reference Shelf, Washington, pp 148-165. https://doi.org/10. 1029/RF003p0148

Fang Y, Elsworth D, Wang C, Ishibashi T, Fitts JP (2017) Frictional stability-permeability relationships for fractures in shales. J Geophys Res Solid Earth 122:1760-1776. https://doi.org/10.1002/ 2016jb013435

Favero V, Ferrari A, Laloui L (2016) On the hydro-mechanical behaviour of remoulded and natural Opalinus Clay shale. Eng Geol 208:128-135. https://doi.org/10.1016/j.enggeo.2016.04.030

Favero V, Ferrari A, Laloui L (2018) Anisotropic behaviour of opalinus clay through consolidated and drained triaxial testing in saturated conditions. Rock Mech Rock Eng 51:1305-1319. https://doi.org/ 10.1007/s00603-017-1398-5

Ferrari A, Favero V, Laloui L (2016) One-dimensional compression and consolidation of shales. Int J Rock Mech Min 88:286-300. https://doi.org/10.1016/j.ijrmms.2016.07.030

Ferrari A, Rosone M, Ziccarelli M, Giger SB (2020) The shear strength of Opalinus Clay shale in the remoulded state. Geomech Energy Envir 21:100142. https://doi.org/10.1016/j.gete.2019.100142

Folk RL (1980) Petrology of sedimentary rocks. Hemphill Publishing Company Austin Texas

Giger SB, Ewy RT, Favero V, Stankovic R, Keller LM (2018) Consolidated-undrained triaxial testing of Opalinus Clay: results and method validation. Geomech Energy Envir 14:16-28. https://doi. org/10.1016/j.gete.2018.01.003

Gräsle W, Plischke I (2010) LT experiment: mechanical behaviour of Opalinus Clay, final report from phases 6-14. Mont Terri Techn Rep TR 2009-07:89

Gräsle W, Plischke I (2011) LT-A Experiment: Mechanical Behavior of Opalinus Clay, data report from Phase 15. Mont Terri Tech Note TN 2010-86:100

Gutierrez M, Vik G, Berre T (1996) Shale Strength As Function of Stress History And Diagenesis. Paper presented at the ISRM International Symposium - EUROCK 96, Turin - Italy 1996/1/1/

Head KH, Epps RJ (2014) Manual of Soil Laboratory Testing, Volume 3: Effective Stress Tests., Third Edition edn. Whittles Publishing,

Heap MJ, Baud P, Meredith PG (2009) Influence of temperature on brittle creep in sandstones. Geophys Res Lett. https://doi.org/ $10.1029 / 2009 \mathrm{~g} 1039373$

Herrmann J, Rybacki E, Sone H, Dresen G (2018) Deformation experiments on bowland and posidonia shale-Part I: strength and Young's Modulus at ambient and in situ pc-T conditions. Rock Mech Rock Eng 51:3645-3666. https://doi.org/10.1007/ s00603-018-1572-4

Holt RM, Fjaer E, Nes OM, Alassi HT (2011) A shaly look at brittleness. American Rock Mechanics Association

Hornby BE, Schwartz LM, Hudson JA (1994) Anisotropic effectivemedium modeling of the elastic properties of shales. Geophysics 59:1570-1583. https://doi.org/10.1190/1.1443546

Hostettler B et al (2017) Litho- and biostratigraphy of the Opalinus Clay and bounding formations in the Mont Terri rock laboratory (Switzerland). Swiss J Geosci 110:23-37. https://doi.org/ 10.1007/s00015-016-0250-3

Hou Z, Gutierrez M, Ma S, Almrabat A, Yang C (2019) Mechanical behavior of shale at different strain rates. Rock Mech Rock Eng 52:3531-3544. https://doi.org/10.1007/s00603-019-01807-7

Houben ME, Desbois G, Urai JL (2014) A comparative study of representative 2D microstructures in Shaly and Sandy facies of Opalinus Clay (Mont Terri, Switzerland) inferred form BIB-SEM and MIP methods. Mar Petrol Geol 49:143-161. https://doi.org/10. 1016/j.marpetgeo.2013.10.009

Hu DW, Zhang F, Shao JF (2014) Experimental study of poromechanical behavior of saturated claystone under triaxial compression. Acta Geotech 9:207-214. https://doi.org/10.1007/ s11440-013-0259-y
Ibanez WD, Kronenberg AK (1993) Experimental deformation of shale-mechanical-properties and microstructural indicators of mechanisms. Int J Rock Mech Min Sci Geomech Abstr 30:723734. https://doi.org/10.1016/0148-9062(93)90014-5

Ikari MJ, Saffer DM, Marone C (2007) Effect of hydration state on the frictional properties of montmorillonite-based fault gouge. J Geophys Res Solid Earth. https://doi.org/10.1029/2006jb004748

Ikari MJ, Saffer DM, Marone C (2009) Frictional and hydrologic properties of clay-rich fault gouge. J Geophys Res Solid Earth. https:// doi.org/10.1029/2008jb006089

Ilgen AG et al (2017) Shales at all scales: Exploring coupled processes in mudrocks. Earth Sci Rev 166:132-152. https://doi.org/ 10.1016/j.earscirev.2016.12.013

Islam MA, Skalle P (2013) An experimental investigation of shale mechanical properties through drained and undrained test mechanisms. Rock Mech Rock Eng 46:1391-1413. https://doi.org/10. 1007/s00603-013-0377-8

Jaeger JC, Cook NGW, Zimmerman RW (2007) Fundamentals of rock mechanics, 4th edn. Blackwell, Malden, Mass, Oxford

Jaeggi D, Bossart P, Wymann L (2014) Kompilation der lithologischen Variabilität und Eigenschaften des Opalinus-Ton im Felslabor Mont Terri. Swisstopo, Wabern

Jaeggi D, Bossart P, Nussbaum C The Rock Mechanical Behavior of Opalinus Clay - 20 Years of Experience in the Mont Terri Rock Laboratory. In: Ferrari A, Laloui L (eds) Advances in Laboratory Testing and Modelling of Soils and Shales (ATMSS), Cham 2017. Springer International Publishing, pp 351-356

Jobmann M et al (2017) Safety assessment methodology for a German high-level waste repository in clay formations. J Rock Mech Geotech 9:856-876. https://doi.org/10.1016/j.jrmge.2017.05.007

Kaufhold A, Grasle W, Plischke I, Dohrmann R, Siegesmund S (2013) Influence of carbonate content and micro fabrics on the failure strength of the sandy facies of the Opalinus Clay from Mont Terri (Underground Rock Laboratory). Eng Geol 156:111-118. https:// doi.org/10.1016/j.enggeo.2013.01.014

Kaufhold A, Halisch M, Zacher G, Kaufhold S (2016) X-ray computed tomography investigation of structures in Opalinus Clay from large-scale to small-scale after mechanical testing. Solid Earth 7:1171-1183. https://doi.org/10.5194/se-7-1171-2016

Keller LM, Holzer L (2018) Image-based upscaling of permeability in Opalinus Clay. J Geophys Res Solid Earth 123:285-295. https:// doi.org/10.1002/2017jb014717

Keller LM, Holzer L, Wepf R, Gasser P (2011) 3D geometry and topology of pore pathways in Opalinus clay: implications for mass transport. Appl Clay Sci 52:85-95. https://doi.org/10.1016/j.clay. 2011.02.003

Keller LM, Holzer L, Schuetz P, Gasser P (2013a) Pore space relevant for gas permeability in Opalinus clay: statistical analysis of homogeneity, percolation, and representative volume element. J Geophys Res-Solid Earth 118:2799-2812. https://doi.org/10. 1002/jgrb.50228

Keller LM, Schuetz P, Erni R, Rossell MD, Lucas F, Gasser P, Holzer L (2013b) Characterization of multi-scale microstructural features in Opalinus Clay. Micropor Mesopor Mat 170:83-94. https://doi. org/10.1016/j.micromeso.2012.11.029

Klinkenberg M, Kaufhold S, Dohrmann R, Siegesmund S (2009) Influence of carbonate microfabrics on the failure strength of claystones. Eng Geol 107:42-54. https://doi.org/10.1016/j.enggeo. 2009.04.001

Kohli AH, Zoback MD (2013) Frictional properties of shale reservoir rocks. J Geophys Res Solid Earth 118:5109-5125. https://doi. org/10.1002/jgrb.50346

Kranz RL, Harris WJ, Carter NL (1982) Static fatigue of granite at $200^{\circ} \mathrm{C}$. Geophys Res Lett 9:1-4. https://doi.org/10.1029/GL009 i001p00001 
Kronenberg AK, Kirby SH, Pinkston J (1990) Basal slip and mechanical anisotropy of biotite. J Geophys Res Solid Earth 95:1925719278. https://doi.org/10.1029/JB095iB12p19257

Kubo T, Katayama I (2015) Effect of temperature on the frictional behavior of smectite and illite. J Miners Petrol Sci 110:293-299. https://doi.org/10.2465/jmps.150421

Kwon O, Kronenberg AK Deformation of Wilcox shale: Undrained strengths and effects of strain rate. In: 1st North American Rock Mechanics Symposium, NARMS 1994 1994. pp 757-765

Laloui L, Salager S, Rizzi M (2013) Retention behaviour of natural clayey materials at different temperatures. Acta Geotech 8:537546. https://doi.org/10.1007/s11440-013-0255-2

Lauper B, Jaeggi D, Deplazes G, Foubert A (2018) Multi-proxy facies analysis of the Opalinus Clay and depositional implications (Mont Terri rock laboratory, Switzerland). Swiss J Geosci 111:383-398. https://doi.org/10.1007/s00015-018-0303-x

Laurich B, Urai JL, Desbois G, Vollmer C, Nussbaum C (2014) Microstructural evolution of an incipient fault zone in Opalinus Clay: Insights from an optical and electron microscopic study of ionbeam polished samples from the Main Fault in the Mt-Terri Underground Research Laboratory. J Struct Geol 67:107-128. https://doi.org/10.1016/j.jsg.2014.07.014

Laurich B, Urai JL, Nussbaum C (2017) Microstructures and deformation mechanisms in Opalinus Clay: insights from scaly clay from the Main Fault in the Mont Terri Rock Laboratory $(\mathrm{CH})$. Solid Earth 8:27-44. https://doi.org/10.5194/se-8-27-2017

Laurich B, Urai JL, Vollmer C, Nussbaum C (2018) Deformation mechanisms and evolution of the microstructure of gouge in the Main Fault in Opalinus Clay in the Mont Terri rock laboratory (CH). Solid Earth 9:1-24. https://doi.org/10.5194/se-9-1-2018

Lisjak A, Tatone BSA, Grasselli G, Vietor T (2014) Numerical modelling of the anisotropic mechanical behaviour of opalinus clay at the laboratory-scale using FEM/DEM. Rock Mech Rock Eng 47:187-206. https://doi.org/10.1007/s00603-012-0354-7

Liu H, Guo W, Liu D, Zhou S, Deng J (2018) Authigenic embrittlement of marine shale in the process of diagenesis. Nat Gas Ind B 5:575-582. https://doi.org/10.1016/j.ngib.2018.11.005

Liu Z, Shao J, Xie S, Conil N, Talandier J (2019) Mechanical behavior of claystone in lateral decompression test and thermal effect. Rock Mech Rock Eng 52:321-334. https://doi.org/10.1007/ s00603-018-1573-3

Logan JM, Freiedman M, Higgs N, Dengo C, Shimamoto T (1979) Experimental studies of simulated gouge and their application to studies of natural fault zones. Proceedings of Conference VIII on Analysis of Actual Fault Zones in Bedrock US Geological Survey, Open File Report, pp 79-1239

Loucks RG, Reed RM, Ruppel SC, Hammes U (2012) Spectrum of pore types and networks in mudrocks and a descriptive classification for matrix-related mudrock pores. Aapg Bull 96:1071-1098. https://doi.org/10.1306/08171111061

Lupini JF, Skinner AE, Vaughan PR (1981) The drained residual strength of cohesive soils. Geotechnique 31:181-213. https:// doi.org/10.1680/geot.1981.31.2.181

Madsen FT (1998) Clay mineralogical investigations related to nuclear waste disposal. Clay Miner 33:109-129. https://doi.org/10.1180/ 000985598545318

Mahanta B, Tripathy A, Vishal V, Singh TN, Ranjith PG (2017) Effects of strain rate on fracture toughness and energy release rate of gas shales. Eng Geol 218:39-49. https://doi.org/10.1016/j.enggeo. 2016.12.008

Mares VM, Kronenberg AK (1993) Experimental deformation of muscovite. J Struct Geol 15:1061-1075. https://doi.org/10.1016/ 0191-8141(93)90156-5

Masri M, Sibai M, Shao JF, Mainguy M (2014) Experimental investigation of the effect of temperature on the mechanical behavior of
Tournemire shale. Int J Rock Mech Min 70:185-191. https://doi. org/10.1016/j.ijrmms.2014.05.007

Mavko G, Mukerji T, Dvorkin J (2009) The Rock Physics Handbook: Tools for Seismic Analysis of Porous Media. 2 edn. Cambridge University Press, Cambridge. https://doi.org/10.1017/CBO97 80511626753

Mazurek M, Hurford AJ, Leu W (2006) Unravelling the multi-stage burial history of the Swiss Molasse Basin: integration of apatite fission track, vitrinite reflectance and biomarker isomerisation analysis. Basin Res 18:27-50. https://doi.org/10.1111/j.13652117.2006.00286.x

McGlade C, Speirs J, Sorrell S (2013) Unconventional gas-a review of regional and global resource estimates. Energy 55:571-584. https://doi.org/10.1016/j.energy.2013.01.048

Menaceur H, Delage P, Tang AM, Conil N (2016) On the thermohydro-mechanical behaviour of a sheared callovo-oxfordian claystone sample with respect to the EDZ behaviour. Rock Mech Rock Eng 49:1875-1888. https://doi.org/10.1007/ s00603-015-0897-5

Mikhail RS, Guindy NM (1971) Rates of low-temperature dehydration of montmorillonite and illite. J Appl Chem Biotech 21:113-116. https://doi.org/10.1002/jctb.5020210407

Milliken K (2014) A compositional classification for grain assemblages in fine-grained sediments and sedimentary rocks. J Sediment Res 84:1185-1199. https://doi.org/10.2110/jsr.2014.92

Minardi A, Crisci E, Ferrari A, Laloui L (2016) Anisotropic volumetric behaviour of Opalinus clay shale upon suction variation. Géotech Lett 6:144-148. https://doi.org/10.1680/jgele.16.00023

Minardi A et al (2020) Benchmark study of undrained triaxial testing of Opalinus Clay shale: results and implications for robust testing. Geomech Energy Envir. https://doi.org/10.1016/j.gete. 2020.100210

Minon S, Salager S, Laloui L (2010) WS-H Experiment: Identification tests and rheological analysis of Opalinus Clay: Shaley facies, Sandy facies and Wet Spot material. Mont Terri Tech Note TN 2010-61:45

Mohajerani M, Delage P, Sulem J, Monfared M, Tang AM, Gatmiri B (2012) A laboratory investigation of thermally induced pore pressures in the Callovo-Oxfordian claystone. Int J Rock Mech Min 52:112-121. https://doi.org/10.1016/j.ijrmms.2012.02.012

Monfared M, Delage P, Sulem J, Mohajerani M, Tang AM, De Laure E (2011a) A new hollow cylinder triaxial cell to study the behavior of geo-materials with low permeability. Int J Rock Mech Min 48:637-649. https://doi.org/10.1016/j.ijrmms.2011.02.017

Monfared M, Sulem J, Delage P, Mohajerani M (2011b) A laboratory investigation on thermal properties of the Opalinus claystone. Rock Mech Rock Eng 44:735. https://doi.org/10.1007/ s00603-011-0171-4

Moore DE, Lockner DA (2004) Crystallographic controls on the frictional behavior of dry and water-saturated sheet structure minerals. J Geophys Res Solid Earth. https://doi.org/10.1029/2003j b002582

Morley CK, von Hagke C, Hansberry RL, Collins AS, Kanitpanyacharoen W, King R (2017) Review of major shale-dominated detachment and thrust characteristics in the diagenetic zone: Part I, meso- and macro-scopic scale. Earth Sci Rev 173:168-228. https://doi.org/10.1016/j.earscirev.2017.07.019

Müller P, Jaeggi D (2012) SO (Sedimentology of the Opalinus Clay), Sedimentary structure in the sandy facies of the Opalinus Clay at Mont Terri rock laboratory. Mont Terri Technical Note TN 2012-45:34

NAGRA (2002) Projekt Opalinuston - Synthese der geowissenschaftlichen Untersuchungsergebnisse. vol NTB 02-03. Technical Report of the National Cooperative for the Disposal of Radioactive Waste. NAGRA, Wettingen, Switzerland 
Naumann M, Hunsche U, Schulze O (2007) Experimental investigations on anisotropy in dilatancy, failure and creep of Opalinus Clay. Phys Chem Earth Parts A/B/C 32:889-895. https://doi.org/ 10.1016/j.pce.2005.04.006

Niandou H, Shao JF, Henry JP, Fourmaintraux D (1997) Laboratory investigation of the behaviour of Tournemire shale. Int J Rock Mech Min 34:3-16. https://doi.org/10.1016/S0148-9062(96) 00053-8

Nüesch R (1991) Das mechanische Verhalten von Opalinuston. Dissertation, ETH Zürich, Switzerland

Nygård R, Gutierrez M, Gautam R, Høeg K (2004) Compaction behavior of argillaceous sediments as function of diagenesis. Mar Petrol Geol 21:349-362. https://doi.org/10.1016/j.marpetgeo.2004. 01.002

Orellana LF, Scuderi MM, Collettini C, Violay M (2018) Frictional properties of Opalinus Clay: implications for nuclear waste storage. J Geophys Res Solid Earth 123:157-175. https://doi.org/10. 1002/2017jb014931

Orellana LF, Giorgetti C, Violay M (2019) Contrasting mechanical and hydraulic properties of wet and dry fault zones in a proposed shale-hosted nuclear waste repository. Geophys Res Lett 46:1357-1366. https://doi.org/10.1029/2018g1080384

Paterson MS, Wong T-F (2005) Experimental rock deformation-the brittle field. Springer Science \& Business Media

Parisio F, Samat S, Laloui L (2015) Constitutive analysis of shale: a coupled damage plasticity approach. Int J Solids Struct 75-76:88-98. https://doi.org/10.1016/j.jisolstr.2015.08.003

Paterson MS (1970) A high-pressure, high-temperature apparatus for rock deformation. Int J Rock Mech Min Sci Geomech Abstr 7:517-526. https://doi.org/10.1016/0148-9062(70)90004-5

Pearson FJ et al (2003) Mont Terri project: geochemistry of water in the opalinus clay formation at the Mont Terri rock laboratory. Reports of the Federal Office for Water and Geology (FOWG) Geology Series No. 5

Peters M, Mazurek M, Jaeggi D, Müller H (2011) WS-H Experiment: Heterogeneities in the sandy facies of Opalinus Clay on a scale on millimetres to centimeters. Mont Terri Tech Note TN 2010-76:66

Petley DN (1999) Failure envelopes of mudrocks at high confining pressures. Geol Soc Lond Spec Publ 158:61-71. https://doi.org/ 10.1144/gsl.Sp.1999.158.01.05

Philipp T, Amann-Hildenbrand A, Laurich B, Desbois G, Littke R, Urai J (2017) The effect of microstructural heterogeneity on pore size distribution and permeability in Opalinus Clay (Mont Terri, Switzerland): insights from an integrated study of laboratory fluid flow and pore morphology from BIB-SEM images. Geol Soc Lond Spec Publ 454:85-106

Popp T, Salzer K (2007) Anisotropy of seismic and mechanical properties of Opalinus clay during triaxial deformation in a multianvil apparatus. Phys Chem Earth 32:879-888. https://doi.org/ 10.1016/j.pce.2006.04.022

Rassouli FS, Zoback MD (2018) Comparison of short-term and longterm creep experiments in shales and carbonates from unconventional gas reservoirs. Rock Mech Rock Eng 51:1995-2014. https://doi.org/10.1007/s00603-018-1444-y

Reisdorf AG, Hostettler B, Waltschew A, Jaeggi D, Menkveld-Gfeller U (2014) SO (Sedimentology of the Opalinus Clay), Biostratigraphy of the Basal Part of the Opalinus-Ton at the Mont Terri rock laboratory. Switz Mont Terri Techn Rep TR 2014-07:29

Rutter EH, Maddock RH, Hall SH, White SH (1986) Comparative microstructures of natural and experimentally produced claybearing fault gouges. Pure Appl Geophys 124:3-30. https://doi. org/10.1007/BF00875717

Rybacki E, Reinicke A, Meier T, Makasi M, Dresen G (2015) What controls the mechanical properties of shale rocks?-Part I: strength and Young's modulus. J Petrol Sci Eng 135:702-722. https://doi.org/10.1016/j.petrol.2015.10.028

Rybacki E, Meier T, Dresen G (2016) What controls the mechanical properties of shale rocks? - Part II: Brittleness. J Petrol Sci Eng 144:39-58. https://doi.org/10.1016/j.petrol.2016.02.022

Saffer DM, Marone C (2003) Comparison of smectite- and illite-rich gouge frictional properties: application to the updip limit of the seismogenic zone along subduction megathrusts. Earth Planet Sc Lett 215:219-235. https://doi.org/10.1016/s0012-821x(03) 00424-2

Salager S, François B, Nuth M, Laloui L (2013) Constitutive analysis of the mechanical anisotropy of Opalinus Clay. Acta Geotech 8:137-154. https://doi.org/10.1007/s11440-012-0187-2

Sammis CG, Lockner DA, Ze R (2011) The role of adsorbed water on the friction of a layer of submicron particles. Pure Appl Geophys 168:2325-2334. https://doi.org/10.1007/s00024-011-0324-0

Schleicher AM, Boles A, van der Pluijm BA (2015) Response of natural smectite to seismogenic heating and potential implications for the 2011 Tohoku earthquake in the Japan Trench. Geology 43:755-758. https://doi.org/10.1130/G36846.1

Schnetzer F, Thissen P, Giraudo N, Emmerich K (2016) Unraveling the coupled processes of (De)hydration and structural changes in Na+-saturated montmorillonite. J Phys Chem C 120:1528215287. https://doi.org/10.1021/acs.jpcc.6b04986

Schuck B, Desbois G, Urai JL (2020) Grain-scale deformation mechanisms and evolution of porosity in experimentally deformed Boom Clay. J Struct Geol 130:103894. https://doi.org/10.1016/j. jsg.2019.103894

Seiphoori A, Whittle AJ, Krakowiak KJ, Einstein HH (2017) Insights into diagenesis and pore structure of Opalinus shale through comparative studies of natural and reconstituted materials. Clay Clay Miner 65:135-153. https://doi.org/10.1346/Ccmn.2017. 064055

Sellin P, Leupin OX (2013) The use of clay as an engineered barrier in radioactive-waste management a review. Clay Clay Miner 61:477-498. https://doi.org/10.1346/CCMN.2013.0610601

Sharma P, Prakash R, Abedi S (2019) Effect of temperature on nanoand microscale creep properties of organic-rich shales. J Petrol Sci Eng 175:375-388. https://doi.org/10.1016/j.petrol.2018.12. 039

Siegesmund S, Popp T, Kaufhold A, Dohrmann R, Grasle W, Hinkes R, Schulte-Kortnack D (2014) Seismic and mechanical properties of Opalinus Clay: comparison between sandy and shaly facies from Mont Terri (Switzerland). Environ Earth Sci 71:3737-3749. https://doi.org/10.1007/s12665-013-2768-2

Sone H, Zoback MD (2013) Mechanical properties of shale-gas reservoir rocks-Part 2: Ductile creep, brittle strength, and their relation to the elastic modulus. Geophysics 78:D393-D402. https:// doi.org/10.1190/geo2013-0051.1

Swan G, Cook J, Bruce S, Meehan R (1989) Strain rate effects in Kimmeridge bay shale. Int J Rock Mech Min Sci Geomech Abstr 26:135-149. https://doi.org/10.1016/0148-9062(89)90002-8

Tembe S, Lockner DA, Wong T-F (2010) Effect of clay content and mineralogy on frictional sliding behavior of simulated gouges: Binary and ternary mixtures of quartz, illite, and montmorillonite. J Geophys Res Solid Earth. https://doi.org/10.1029/2009j b006383

Thury MF, Bossart PJ (1999) Mont Terri Rock Laboratory: Results of the hydrogeological, geochemical and geotechnical experiments performed in 1996 and 1997. vol Geologischer Bericht Nr. 23. Landeshydrologie und-geologie,

Tsang CF, Barnichon JD, Birkholzer J, Li XL, Liu HH, Sillen X (2012) Coupled thermo-hydro-mechanical processes in the near field of a high-level radioactive waste repository in clay formations. Int J Rock Mech Min 49:31-44. https://doi.org/10.1016/j.ijrmms. 2011.09.015 
Valès F, Nguyen Minh D, Gharbi H, Rejeb A (2004) Experimental study of the influence of the degree of saturation on physical and mechanical properties in Tournemire shale (France). Applied Clay Science \$V 26:197-207

Van Loon LR, Soler JM, Muller W, Bradbury MH (2004) Anisotropic diffusion in layered argillaceous rocks: a case study with opalinus clay. Environ Sci Technol 38:5721-5728. https://doi.org/10. 1021/es049937g

Vöbel T, Gräsle W, Plischke I (2014) LT-A Experiment: strength and deformation of Opalinus Clay: data report from phase 19. Mont Terri Tech Note TN 2014-06:52

Wenk HR, Voltolini M, Mazurek M, Van Loon LR, Vinsot A (2008) Preferred orientations and anisotropy in shales: Callovo-Oxfordian shale (France) and opalinus clay (Switzerland). Clay Clay Miner 56:285-306. https://doi.org/10.1346/Ccmn.2008.0560301

Wild KM, Amann F (2018) Experimental study of the hydro-mechanical response of Opalinus Clay-Part 1: pore pressure response and effective geomechanical properties under consideration of confinement and anisotropy. Eng Geol 237:32-41. https://doi. org/10.1016/j.enggeo.2018.02.012

Wild KM, Wymann LP, Zimmer S, Thoeny R, Amann F (2015) Water retention characteristics and state-dependent mechanical and petro-physical properties of a clay shale. Rock Mech Rock Eng 48:427-439. https://doi.org/10.1007/s00603-014-0565-1

Yamaguchi A et al (2011) Progressive illitization in fault gouge caused by seismic slip propagation along a megasplay fault in the Nankai Trough. Geology 39:995-998. https://doi.org/10.1130/g32038.1

Yu C et al (2017) Comparative study of methods to estimate hydraulic parameters in the hydraulically undisturbed Opalinus Clay (Switzerland). Swiss J Geosci 110:85-104. https://doi.org/10. 1007/s00015-016-0257-9

Ze R, Lockner DA (2010) Fault weakening and earthquake instability by powder lubrication. Nature 467:452-455. https://doi.org/10. 1038/nature09348
Zhang C-L (2017) Examination of effective stress in clay rock. J Rock Mech Geotech 9:479-489. https://doi.org/10.1016/j.jrmge.2016. 07.008

Zhang C-L, Laurich B (2019) Mechanical behavior of sandy facies of Opalinus Clay under different load conditions. J Rock Mech Geotech. https://doi.org/10.1016/j.jrmge.2019.09.005

Zhang C-L, Rothfuchs T, Su K, Hoteit N (2007) Experimental study of the thermo-hydro-mechanical behaviour of indurated clays. Phys Chem Earth Parts A/B/C 32:957-965. https://doi.org/10. 1016/j.pce.2006.04.038

Zhang F, Xie SY, Hu DW, Shao JF, Gatmiri B (2012) Effect of water content and structural anisotropy on mechanical property of claystone. Appl Clay Sci 69:79-86. https://doi.org/10.1016/j. clay.2012.09.024

Zhang DC, Ranjith PG, Perera MSA (2016) The brittleness indices used in rock mechanics and their application in shale hydraulic fracturing: a review. J Petrol Sci Eng 143:158-170. https://doi. org/10.1016/j.petrol.2016.02.011

Zhang C-L, Conil N, Armand G (2017) Thermal effects on clay rocks for deep disposal of high-level radioactive waste. J Rock Mech Geotech 9:463-478. https://doi.org/10.1016/j.jrmge.2016.08.006

Zoback MD (2007) Reservoir Geomechanics. Cambridge University Press, Cambridge

Publisher's Note Springer Nature remains neutral with regard to jurisdictional claims in published maps and institutional affiliations. 